\title{
Health Resorts and Multi-Textured Perceptions of International Health Tourists
}

\author{
Salman Majeed ${ }^{1, *}$, Changbao Lu ${ }^{1, *}$, Mahwash Majeed ${ }^{2}$ and Muahmmad Naeem Shahid ${ }^{3}$ \\ 1 School of Economics and Management, Fuzhou University, Fuzhou 350002, China \\ 2 Department of Applied Psychology, GC University, Faisalabad, Punjab 38000, Pakistan; \\ mahwash.md1@gmail.com \\ 3 School of Management Studies, The University of Faisalabad, Faisalabad, Punjab 38000, Pakistan; \\ naeemtuf@yahoo.com \\ * Correspondence: m150719001@fzu.edu.cn (S.M.); luskyfei@sina.cn (C.L.); Tel.: +86-(0)591-228-66200 (C.L.)
}

Received: 15 March 2018; Accepted: 29 March 2018; Published: 3 April 2018

\begin{abstract}
Health and medical tourism is considered one of the fastest growing segments of the tourism industry. Recently, research on health resorts has been gaining academic attention in tandem with the positive contribution of the health and medical segments to the tourism industry. The purpose of this study is to better conceptualize how the behavioral intentions of health tourists are shaped in the emerging context of the health resort. This study illuminates the likely perceptions of prospective tourists about the attractions of health resorts, and endeavors to examine the response of health tourists using data from 359 international health tourists/travelers, comprising of Thai, Indian, and Chinese nationalities. The study also uses the partial least square structural equation modeling (PLS-SEM) technique in order to analyze the responses of international tourists gathered at two international airports in China. The present study shows that tourists' expectations and their behavioral intentions are generally associated indicators of perceived health resort attractions. Expectations play a significant mediating role, while culture impacts the overall phenomenon of proposed associations in a moderating way. Moreover, sustainable tourism attractions also play a significant role in shaping Thai travelers' behavioral responses, while medical facilities and risk levels are considered significant in determining Indian and Chinese travelers' behaviors. By developing theoretical and empirical grounds, this study offers implications for further research and development in health resorts and other niches of health tourism.
\end{abstract}

Keywords: health tourism; medical tourism; health resort; sustainable tourism; tourist behavior; culture

\section{Introduction}

Tourism has been changing its nature rapidly in recent years due to the amalgamation of the health and medical industries in tandem with tourists' complex quests for rest, relaxation, leisure, fun, and sustainable tourism attractions in order to find overall improvement in their quality of life $[1,2]$. It is noted that many individuals are moving across national borders to find their optimal health status [3-5]. While this style of human movement is similar to tourism, it is different from conventional traveling in terms of pleasure and rest, and is commonly termed medical tourism [6,7]. More precisely, medical tourism involves two different segments, that is, medicine and tourism, which have been deeply interlinked as of late [6,8]. However, these segments fall into a broader sense of health and maintenance, because individuals travel offshore in order to seek different diagnostic treatments, surgeries, dental care, cosmetic reasons, and lifestyle enhancement treatments/therapies, as well as holiday and vacation in therapeutic places [2]. Despite medical interventions while traveling abroad, 
it is noted that medical tourists travel across the world in order to find better quality of life, and hence, medical tourism is often encapsulated into notions of health tourism as well [9]. Reddy et al. [10] further fueled the interlinked phenomenon of medical and health tourism, and noted it in terms of health and wellness tourism by narrating that medical tourists travel abroad for different health and wellness treatments, which may include alternative therapies, such as for example, spa, in health and wellness centers in tandem with experiencing tourism. Hence, health tourism is a broader umbrella term in order to include different conceptualizations of medical, health, wellness, and tourism $[1,2]$. It is noted that health and medical tourism have pervasively contributed to developing positive economic indicators for the participating destinations in health and medical tourism [11-13]. For example, Cuba is enjoying $10 \%$ of its total national gross domestic product (GDP) from the country's health and medical tourism sectors [14], India earns US\$2.3 billion yearly from its health and medical tourism [15], and the private sector of the United Kingdom (UK) earns $25 \%$ of its revenue from the $7 \%$ of international patients coming to the UK for their medical or health treatments [16], to name a few. Consequently, many countries across the globe are actively participating in health and medical tourism in order to positively boost their economic indicators [17,18]. For example, Majeed et al. [2] noted that there are 96 participating countries in medical tourism business, which are serving about 780 million tourists worldwide. From this perspective, it is noted that many countries are emerging as medical and health tourism destinations in Asia; for example, China, South Korea, Thailand, and India; in Europe, for example, Germany, Poland, and Hungary; in Latin America, for example, Brazil, Mexico, and Costa Rica; and in Africa, for example, South Africa and Cuba, etc. [1]. Since medical and health tourism are moving parallel in their core nature, that is, health and well-being, the role of participating health and medical tourism destinations is getting more important in the present context in order to globally serve the varied health care preferences of consumers.

Health tourism involves medical treatments for optimal health and wellness notions. These notions are now perceived as achievable alongside the other attractions of sustainable tourism, such as for example, healthy food, comfortable accommodation, sightseeing, fresh air, clean water, beaches, natural landscapes, and adventure $[10,17]$. This is because the phenomenon of natural healing is directly related to the quality of the surrounding environment [18]. Moreover, it is noted that the quality of one's environment also determines the quality of one's health [19]; hence, it arguably comes under the scope of sustainable tourism. From this perspective, it can further be narrated that health tourism is highly concerned with the concept of a health place that offers infrastructure comprising of health facilities, necessary medical intervention, aesthetic services, and sustainable tourism attractions, for example, lodging, food and beverages (F\&B), rentals, adventure, a pollution-free environment, fresh air, and mineral and thermal water therapies [17,20-23]. Different scholars have noted the concept of a health place; however, their associated terminologies sometimes differ. For example, some scholars note them as therapeutic places [24,25], while others document this concept by calling such a place a health resort $[26,27]$. Although the concept of a health resort is passing through its embryonic stage, the concept is still vague. Nevertheless, it demands profound theoretical underpinnings in order to appropriately address health and wellness notions. Considering the biological connections among health, medicine, wellness, rest, relaxation, therapies, and alternative medicine treatments, the term "health resort" is considered appropriate to be used in the present study context. However, we will also provide some additional theoretical support in order to ensure consistency in different health care dimensions, and endeavor to contribute to the academic literature of health and medical tourism by encapsulating the broader notions of health and wellness into its emerging scope on empirical research grounds.

Health resorts include treatments and recovery places where tourists/travelers/patients may rest after being operated on, with or without experiencing alternative therapies. However, the insufficient availability of medical/health facilities in traditional hospitals/clinics/medical care centers has been noted previously in the academic literature [26-31]. In this scenario, a health infrastructure is meanwhile emerging that offers differentiated therapeutic places, medical facilities, 
appropriate medical supervision, traditional and complementary medicine (T\&CM) treatments, alternative therapies, such as yoga for example, and health care experience with notions deeply grounded in the preferences of tourists/travelers for natural healings [2,20,24,26,27,32-35], which also further fertile the conceptual grounds of the health resort. However, little academic attention has been observed that addresses the attractions and importance of the health resort in the health and tourism industries. Moreover, the attractions that international travelers may perceive and expect in a health resort context have not been analyzed in sufficient detail in the previous literature.

Many research works have identified the crucial role of individuals' perception and evaluation in defining behavioral intentions $[19,36,37]$. More precisely, expectations are discussed in determining tourists' decision-making processes and their likely behavioral intentions in health and medical tourism contexts [1,2,38-41]. However, despite the seminal role of expectations, there has been little literature that attempts to empirically examine the role of expectations in determining international health tourists' / travelers' behavioral intentions more precisely in a health resort concept. Additionally, empirical grounds for the likely relationships between the expectations of health tourists, evaluations of the attractions of a health resort, and their impact on their ultimate behavioral intentions are succinct. Scholars generally agree that cultural differences may influence tourists' / travelers' behavioral intentions [42-44]. However, such cultural implications are complicated to determine, even though they are considered important by the tourism stakeholders in order to define appropriate strategies for delivering satisfied tourism experiences to international tourists/travelers by meeting their expectations [42,45]. From this perspective, it is important to note that culture has its own role in determining international tourists' / travelers' behavioral intentions for their health and wellness treatment while traveling globally. However, research that addresses the role of culture in shaping health tourists' behavioral intentions in a health resort context is yet limited.

Addressing the mentioned research gaps, the present study endeavors to propose and validate a research model that examines and helps understand the behavioral intentions of international health tourists in the emerging context of a health resort. Moreover, the purpose of the study is also to better meet the preferences and expectations of international health tourists for their health treatments. Determining such expectations is complex due to travelers' distinct cultural backgrounds, as well as the availability of a variety of medical care, wellness treatments, and tourism opportunities that have been rapidly changing in the recent past [2].Hence, the probable associations among international health tourists' perceptions and their evaluation of attractions for visiting a health resort, expectations, and behavioral intentions on empirical grounds are examined through the partial least square structural equation modeling (PLS-SEM) technique, by using data from 359 respondents comprising of Thai, Indian, and Chinese tourists/travelers at two international airports in China. This woven phenomenon is elucidated in a proposed research framework in the present study in order to testify the impact of expectations as a mediator on the relationship between perceived health resort's attractions and health tourists' / travelers' behavioral intentions. Further, the proposed research framework attempts to investigate whether culture moderately impacts the associations among perceived attractions of a health resort as well as expectations and behavioral intentions of Thai, Indian, and Chinese health tourists/travelers. This study offers theoretical underpinnings and discussions on the interlinked phenomena of health, medical, and sustainable tourism working together in order to develop and refine the concept of a health resort. This study has two important contributions to the budding knowledge of the health, medical, wellness, and tourism industries. First, theoretical concept development is undertaken in an attempt to remove the vagueness from the concept of the health resort, which is in its infancy. Second, the developed concepts of the health resort are empirically examined by gathering the responses of international tourists/travelers. Hence, this study attempts to stitch the broken connections of theory and its validation with some empirical findings. This study will not only contribute to filling theoretical gaps, it will also support future research work by providing a direction and platform through its empirical findings. Moreover, limitations surrounding the present study are documented after the discussions and implications. 


\section{Theoretical Background}

\subsection{Medical, Wellness, and Health Tourism}

Medical tourism is a combination of two service industries: medical and tourism [6,8]. It is noted that medical tourism involves international traveling for various medical and health reasons, for example, major surgeries (cardiovascular surgery, knee replacement, liposuction, etc.) and minor surgeries (dental implants, oral and maxillofacial surgery, etc.) in tandem with experiencing the natural treatments and tourism attractions of a host destination in order to bring overall improvement to an individual's health and wellness status [2]. It is noted that individuals maintain their physical, mental, and spiritual health with medical and health tourism [46], and hence, medical tourism has become a rapidly emerging segment of the tourism industry [47,48]. From this perspective, the boom of medical tourism has offered opportunities and challenges for the health and tourism industries across the world, for example, in Latin America and Australia as well as countries in Europe, Africa, and Asia [1,49]. More precisely, this expansion is found among the developing countries of the world, which has changed the nature of healthcare concepts being applied in the participating destinations and their surrounding environments [2,50].

Some scholars note wellness tourism separately from medical and health tourism in terms of alternative therapies, rest and relaxation, surgical treatments, etc. [18,51]. Hall [52] documents that the core nature of medical tourism is curative, and wellness tourism may be preventive. Ellis [51] differentiates medical tourism from wellness tourism by stating that medical tourism involves traveling to different places for medical procedures or cosmetic enhancement surgeries, while wellness tourism involves traveling to different places in order to find location-based therapies for personal health and well-being. Since medical tourism involves offshore traveling in order to find health and wellness treatments [10], some scholars note that health tourism could be used as an umbrella term for medical and wellness tourism [53]. For example, García-Altés [54] and Kušen [55] note medical tourism in terms of health tourism. Some other scholars note medical tourism by developing links to medical treatments, health treatments, spa [2,56], dental works, cosmetic surgeries, and conventional tourism [22,57] in order to bring overall improvement to one's quality of life. Moreover, wellness tourism, more precisely, spa tourism, etc. [21] has also been linked to the conceptuality of health tourism. Ellis [51] additionally notes medical, wellness, and health tourism constructs, and mentions that the health tourism segment is somehow considered to be an amalgamation of medical and wellness constructs. Hall [21] notes health tourism components by incorporating classifications made by Goeldner [58], which include leisure tourism (where sun and fun activities are done); wellness tourism (in terms of traveling for massage, sauna, spa, climate change, or other activities where the primary purpose is health); and medical/dental tourism (where medical procedures are involved).Since these notions are grounded in the health and wellness of individuals with inseam constructs of medical procedures or life enhancement surgeries, the umbrella term "health tourism" will be used in this study. This is because of the overlapping boundaries of medical, wellness, and health tourism and for the sake of clarity and convenience in order to encapsulate the important concepts of medical treatments, alternative therapies, location-based therapies, and lifestyle enhancement treatments, as well as tourism, in order to address health and quality of life notions. This concept will further be solidified in the next section, which discusses the concept of the health resort.

\subsection{Health Resort's Perceptions and Attraction with Sustainable Tourism}

The rapid growth of health tourism has illuminated the emerging concept of the health resort. A synthesis of the literature on health resorts is passing through its embryonic stage; however, this study will endeavor to develop the concept of health resort and elucidate its perceived functionality. It is noted that individuals travel outside of their natural health care setups in order to find better health, recovery, and possible medical interventions $[59,60]$. This generates a need for a health infrastructure that can ensure and appropriately satisfy individuals' quests for health and recovery with possible 
medical and health treatments. From this perspective, the concept of the health resort is painted on the canvas of the present study. In terms of definition and functionality, a health resort is referred to a geographical area that offers hotel accommodation, entertainment, relaxation, and recreational activities as well as various medical, health, and aesthetic services [61-63]. The term "health resort" often encapsulates "sanatorium-resort complex" into its breadth and depth for health, hospitality, and medical care notions. A sanatorium-resort complex points to a dedicated facility that provides medical interventions, rehabilitation with natural remedies, holiday camps, tourism opportunities, and economical accommodation, as well as various man-made wellness attractions for the tourists / patients, such as for example dietary plans, therapies, and remedial gymnastics [20,64]. Considering the functional similarities between the concepts of the health resort and the sanatorium-resort complex, this study will use the umbrella term "health resort" in order to further discuss the importance and functionality of the health services that are offered to tourists/travelers/patients in certain dedicated facilities and/or geographical areas. Hence, the mentioned notions of health resort reveal that the services of a health resort are aimed at improving the health and wellness of individuals. People travel in order to find a balanced association between their physical, mental, psychological, and social states in tandem with lifestyle therapies [54], which come under the scope of wellness concept. The definition and concept of a health resort that is presented in this study may support the notion that health resorts can play a role in developing a harmonized association between wellness's domains, because they offer rehabilitation with alternative means of care other than conventional western medicine and drugs. Hence, health travelers' quest for optimal health, wellness, and recovery can be grounded appropriately in health resort establishments.

Majeed et al. [2] note the theoretical underpinnings of health and medical tourism trends by presenting the medical tourism and treatment motivation (MTTM) model, which encapsulates some emerging concepts of the health, medicine, and tourism industries. The MTTM model premises narrate that health consumers' preferences are changing rapidly and moving towards the associated constructs of health, wellness, and tourism treatments by adopting a blend of conventional Western medical treatments and natural treatments for better quality of life (Figure 1). The MTTM model premises are further supporting and are conducive to developing the concept of the health resort, which is in its infancy at this stage. This is because the MTTM paradigm emphasizes the provision of health treatments in order to satisfy the changing preferences of health tourists by engaging with different domains of health, medicine, and tourism, as well as rehabilitation, which are the core constructs of a health resort setup. Hence, the multi-textured preferences of modern health care consumers need an appropriate health care infrastructure that may meet their demands appropriately. Since medical tourism is conventionally described in terms of a system that is corrective, episodic, and primarily based on medical interventions that demand a sophisticated medical facility $[65,66]$, health resorts can be described as an appropriate health establishment in order to address the preferences of health tourists/travelers and support the concept of medical tourism as well, because it offers clinical care and the desired medical intervention under the supervision of professional healthcare providers [64]. Hence, medical treatments in a health resort encapsulate the scope of medical tourism into its emerging conceptuality in tandem with the notions of health tourism [55]. Moreover, yoga, massage, spa, and traditional and complementary medicine (T\&CM) treatments (for example, Chinese traditional medicine, Ayurveda, naturopathy), may best be experienced at a specified health location and under medical supervision $[2,28,61,65]$. It is noted that the emerging concepts of health care and medical treatments have deeply influenced the health, medical, and tourism industries with their effective wellness philosophies $[44,53]$. 


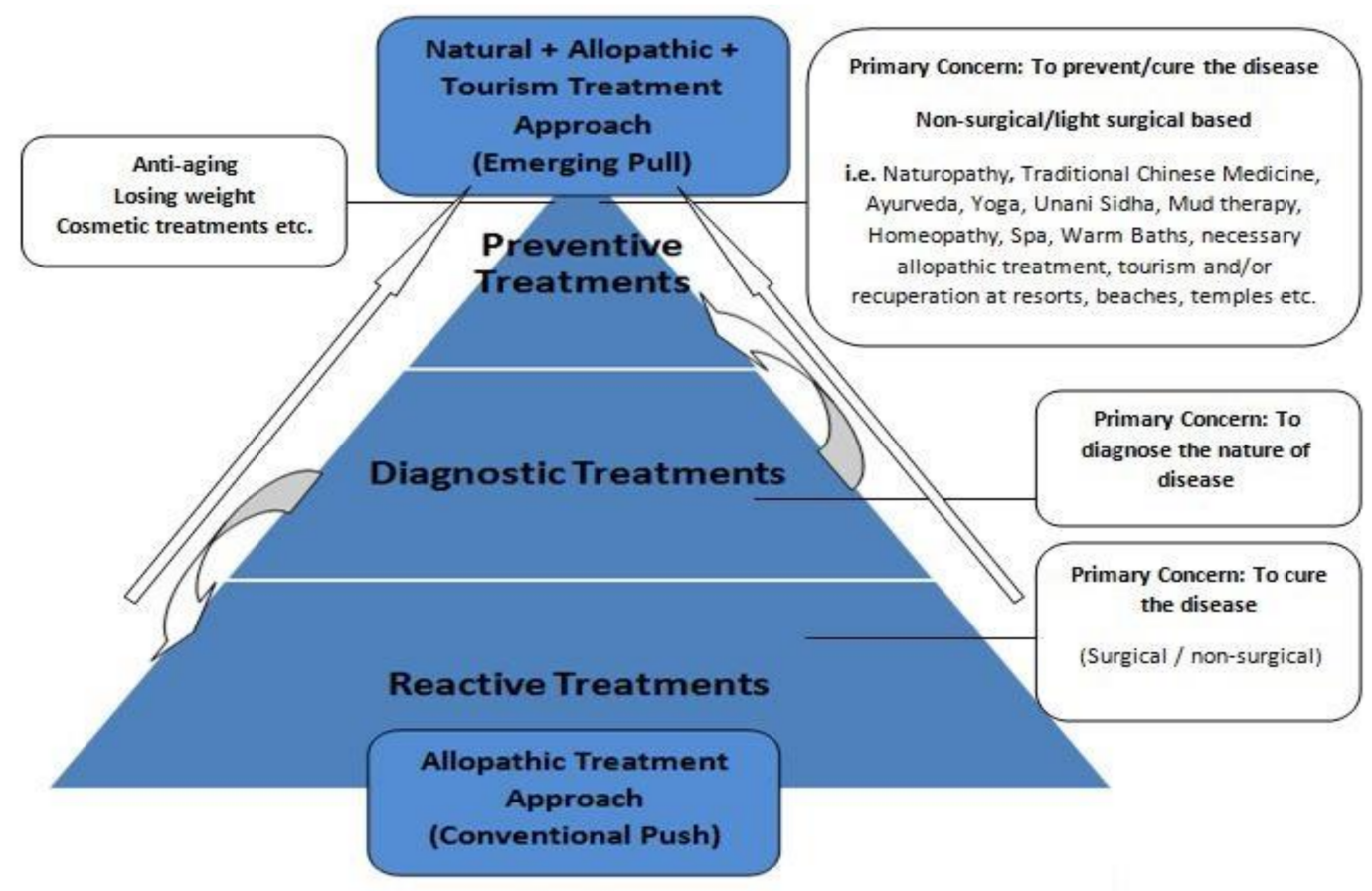

Figure 1. Medical tourism and treatment motivation (MTTM) model. Adapted from Majeed et al. [2].

Despite offshore traveling for major surgeries, for example, hip replacement and heart surgeries, tourists often travel internationally in order to combine their beautification treatments with a vacation, which may include wrinkle removal, face lift, skincare, etc. [67]. Konu et al. [63] note that health and wellness concepts are interlinked where tourism plays a synergistic role and can be primarily associated with the quality of landscapes and the natural environment. Smith and Puczkó [18] note that Finnish and Australian people often associate their wellness notions with nature-based tourism in tandem with recreation outside. From this perspective, some scholars document that the concept of environmental sensitivity is very important in perspectives of health and wellness [68]. It is noted that air quality and pollution levels are antecedents to poor health, and create a risk of premature mortality, respiratory problems, and hospitalization [19]. This concept is especially appropriate in order to develop the concept of the health resort, because after operations people sometimes prefer to rehabilitate at beaches or other tourism sites $[2,10]$. This preference generates a serious concern regarding the environment, and arguably comes under the scope of nature-based tourism in tandem with making its magnetic connections to sustainable tourism notions. Some scholars note that clean water, fresh air, and natural landscapes are counted as environmental assets of a health services-providing destination, which are further accompanied by tourism attractions [17]. Some destinations are blessed with natural resources, for example, wildlife habitats, coral reefs, and sandy beaches, and hold enormous potential to offer recreational experiences and entertainment with environmental protection grooming [69]. It is noted that international and domestic tourists are more prone to experience medical treatments and therapies that might be based on natural healing phenomenon [19]. Hence, the importance and attraction of a clean natural environment and sustainable tourism are obvious while developing the health resort literature.

In order to meet the specific demands of health care consumers, it is noted that many business organizations of different ownerships locate themselves near health resorts that perform various tourism activities and offer other recreational attractions with natural healing treatments [26]. These ownerships offer specialized medical vehicles that are affordable and luxurious, hospitality services, food and beverages (F\&B), and medical agents/brokerage house services that assist with tourism and other medical trips [70,71]. Since medical tourism and health tourism are interlinked 
concepts, medical tourism with health benefits may influence and attract tourists by offering and highlighting medical and healthcare facilities in tandem with other tourism attractions of the host destination [37]. A location's attractions, such as for example the environment, landscapes, aesthetic view, relaxation [72,73], as well as medical and healthcare infrastructure, comfortable transportation, and skilled medical/health/tourism professionals, may help to develop competitiveness among health services providing destinations [74].

Although successful medical treatment, healthcare, and quality lifestyle are the final products of medical and health tourism, health treatments with tourism often reveal tourists' perceptions of their health-related risks. The term "risk" refers to a cognitive conflict between an individual's perceptions, expectations, and possible end results [75]. Mitchell and Vassos [76] note that perceived risks may be higher in tourism, because it is hard to standardize tourism service due to its intangible nature. Despite considering the critical nature of surgical treatment, all surgeries involve a certain level of risk. It is noted that medical and health tourism might involve the risk of offshore medical malpractice, poor quality of medical treatments, difficulties in scheduling follow-up visits with physicians/surgeons, and the transmission of infectious disease $[77,78]$. Some tourists seriously consider postoperative complications, as well as the expenses on corrective medical procedures, costs of living, and revisiting a medical or health care facility, etc. [47]. Prospective medical and health tourists often rely on information provided by the doctors and medical travel agents. This is because tourists have no health-related technical information while deciding to travel offshore for their health treatments, and feel the possibility of high risk associated with their health traveling decision $[75,79,80]$. It is noted that tourists' attitudes and behavioral intentions are influenced significantly by the perceived risks involved in medical and health tourism [81,82]. In continuance of this discussion and for a sustainable development of tourism destinations, Mawby et al. [83] note, with reference to Brasov's safety audit, that risk and security are broader concepts that require particular attention from industrial stakeholders while developing a tourist destination. The authors keep emphasizing that tourists are very much concerned about their access to good medical care as well as safety measures in order to apprehend theft, robberies, strikes, kidnappings, and other diseases (for example, hepatitis, flu, and viruses). Hence, tourists demand safety, guarantee, and detailed information in order to balance medical care outcomes against the potential risks associated with health/wellness treatments as well as other societal risks $[48,83,84]$. Moreover, in a general sense, perceptions of risks underlying images of tourism destinations may determine the success or failure of a tourist destination or otherwise [85]. Lower risk protocols adopted by health/medical destination may act as attractions for health tourists. It is important to mention that providing all kinds of medical, health, and wellness services with tourism/hospitality attractions of such physical settings is difficult. On the whole, healthcare/medical services that medical tourists can afford at a health resort are not similar to the offerings that ordinary medical travelers/tourists experience at conventional health facilities, such as for example, hospitals and clinics. Health tourism consumers perceive and evaluate health services with their associated outcomes, and further link these to medical infrastructure, affordability levels, potential risks, and tourism sustainability when staying at a health resort [61].

\subsection{Expectations Confirmation Theory (ECT)}

Among the concepts of health, wellness, medical, pleasure, and relaxation, some psychological concepts further unfold, such as hopes, expectations, and a consumer's overall satisfaction [86]. However, a patient's overall satisfaction is a system that compares perceptions with expectations, may generate value for money and loyalty, and develop positive behavioral intentions among health care consumers [41]. These concepts become further important when placed into the health care industry [87]. Health care services providers are attempting to address tourists' perceptions and expectations by delivering quality care. By doing so, it is noted that they are uplifting their service delivery standards [88]. 
Consumers' perceived satisfaction and dissatisfaction levels may be determined by under-fulfillment or over-fulfillment of their expectations. Considering the health complexities of the postoperative period, which can include surgical side effects, accessing adequate corrective health treatment with additional costs, and recourse for redressed skin, it is noted that health tourists/travelers expect detailed information about their health treatment, including the medical services to be delivered, the surgical procedure to be performed, likely surgical side effects, and rehabilitation time, with safety and a guarantee in order to dispel perceived surgical/medical threats [80,84]. Expectation confirmation theory (ECT), as put forth by Oliver [89], proposes the premises of expectations, satisfaction, and behavioral intentions by stating that customers may be satisfied if the product or service exceeds their expectations, which pass through their confirmatory perceptual filters. Meanwhile, the same psychological confirmatory filters may result in customers' dissatisfaction if the product or service doesn't meet their expectations [90]. These interlinked ECT phenomena are presented in Figure 2.

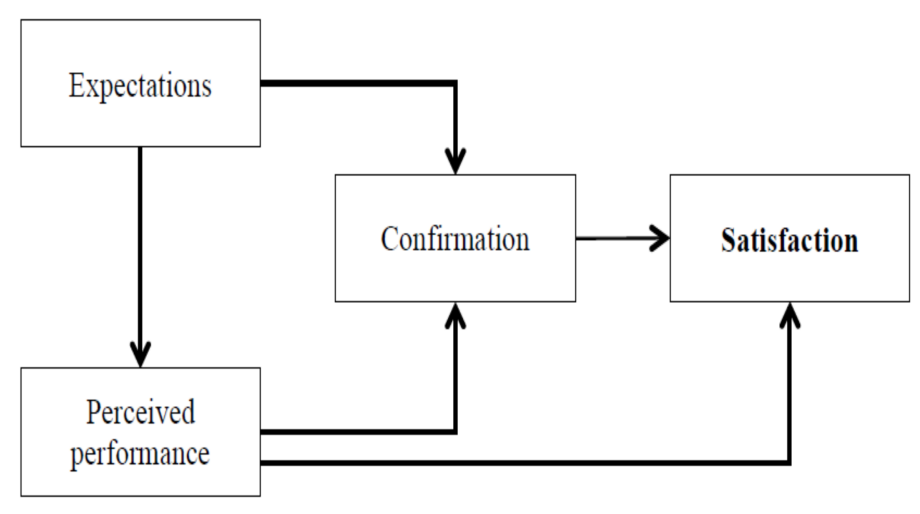

Figure 2. Expectation confirmation theory (ECT). Source: adapted from Oliver [89].

The concept of ECT is important for the consideration of services that are intangible and complex. It enables an evaluation of the performance quality of health and medical services (with some tangible aspects), for example, where international health tourists may not be familiar with the destination's health and tourism offerings. Consumers of health tourism may develop certain expectations before traveling to a health tourism destination for their desired medical and health care reasons. In order to meet the expectations of tourists/travelers, many tourism services providers offer surgical packages in tandem with recuperation in a beautiful tourism location, for example, facelift and recuperation while doing safaris or sightseeing [91-93]. Yang [94] noted the premises of the Kano model in the healthcare industry, showing that healthcare consumers are delighted when the quality of a service/product is beyond their expectations, leading to positive behavioral intentions. Hence, a variety of perceptions and expectations of tourists may influence their behavioral intentions [95]. However, positive behavioral intentions could be developed by generating effective communication on how to find the appropriate health tourism, medical treatments, and suitable doctor/physician, which may be orthogonal to positive behavioral intentions in relation to visiting a health services-providing destination [96].

\section{Theory of Planned Behavior (TPB)}

The decision-making processes of tourists/travelers have gone through substantial developments recently [97]. However, a unifying theory that perfectly fits into the context of a health resort's decision-making is yet to be explored. Ajzen and Fishbein's [98] proposed theory of reason action, which was later developed by Ajzen [99] as a theory of planned behavior (TPB) with further connections to behavioral intentions, has been tested in different research fields. TPB is noted as a psychological model that encapsulates the conceptuality and prediction of individuals' behavior through their intentions and other possible influencing factors [100]. Individuals' perceptions may differ from their 
actual abilities to perform certain behaviors, which may ultimately impact their expectations and behavioral intentions. Positive and negative perceptions about the likelihood of the associated results of the behavior may determine consumers' decision-making, for example, negative beliefs about the competency of doctors and the quality of health care. It is noted that negative beliefs and resultant efforts to address the negative results may bring positive behavioral intentions that are conducive to the growth of the business as well [101]. Hence, perceptions and behavioral intentions have been appropriately linked and addressed in the TPB. The attributes of health and medical tourism are linked to the provision of quality medical treatments, which further influence tourists' perceptions and behavioral intentions $[2,22,78]$. The concept of quality medical treatment encapsulates the perceptions of medical/health quality, service quality, and other attributes of rest and enjoyment [101]. In addition to the perceptions, benefits, and attractions of visiting a health destination, perceived risks are also an important determinant of predicting and shaping behavioral intentions, because attitudes are shaped collectively by perceived benefits and perceived risks [102-104].

The TPB has been tested in over 200 studies where health-related behaviors were examined [105], such as for example, healthy diet eating behavior [106], exercise and associated behavior [107,108], and clinicians' behavior [109]. Moreover, the TPB premises have been examined in different studies in order to analyze the behavior of travelers in perspectives of holiday choice and destination [110], traveling attitudes of tourists [111], and restaurant choice behavior [112]. Hence, the application of TPB in the health, travel, and hospitality industries solidifies the robust notions of the application of TPB in predicting intentions and associated behaviors of tourists visiting or intending to visit a health services-providing destination. From this perspective, this study will endeavor to develop the grounds of the related behaviors of health tourists to a health resort, because a health resort also encapsulates a variety of health, travel, hospitality, and travel-related notions into its emerging scope.

The premises of ECT, the Kano model, and TPB provide robust insights that can help develop the theoretical grounds for a health resort's conceptuality. These will further unfurl their theoretical underpinnings in order to examine the linkages between perceived attractions, benefits, risks, and attractions in visiting health resort setups, which additionally encapsulate health, medical, and sustainable tourism attractions into its emerging scope. Some hypotheses are proposed on the basis of the aforementioned discussions of a health resort's perceptions, attractions, and expectations as well as behavioral intentions. The variables considered in the present study, that is, the perceived attractions of the health resort in terms of its affordability, risk level, medical facilities, sustainable tourism, expectations, and behavioral intentions have been brought into the discussion with their proposed relationships as:

Hypotheses 1(H1). The perceived attractions of a health resort have a significantly positive influence on the behavioral intentions of tourists.

Hypotheses 2(H2). Tourists' expectations of a health resort significantly mediate the relationship between their perceptions of the health resort, and their behavioral intentions.

\subsection{Impact of Culture on Behavior}

Luna and Gupta [113] note the etic definition of culture as "the collective programming of the mind which distinguishes the members of one group or category of people from another". It has been documented that culture exerts its influence in shaping consumer's behavior [114]. Some scholars note the impact of national cultural norms on consumer's behavior in different fields [115-117]. In health and medical perspectives, An [45] notes the cultural differences and behaviors of American, Russian, Chinese, and Japanese tourists, interlinking their perceptions of traveling and desired medical and health care treatments. The author documents that the considerations and behavior of tourists towards their health risk, travel risk, costs, and convenience widely differs across different nations due to their distinct cultural values. Schumann et al. [118] perform a cross-cultural comparison of 11 countries (including Thailand, India, and China) in order to examine and compare consumers' behavior in 
relation to service quality and behavioral intentions, and reveal a moderating impact of culture on consumers' behavior. Roongrerngsuke and Liefooghe [119] note the associations among generational differences, national culture, work-related values, and workers' perception of their organization's attractiveness in Thailand, India, and China. The authors note significant cultural and generational differences in the perceptions of gold-collar workers regarding organizational attractiveness. From the tourism perspective, many scholars have noted the importance of national culture and its impact on the decision-making behavior of travelers $[43,120]$. Hence, discussed theoretical grounds highlight that national culture exerts its influence on the behaviors of different cultural inhabitants, and cross-cultural differences exist between people of different nations. These premises provide supporting grounds to further plough the research grounds in order to measure the response of tourists/travelers from Thailand, India, and China. The discussed theoretical grounds assist to postulate that:

Hypotheses 3(H3). Culture has a significantly positive influence on the association between perceived attractions of a health resort, tourists' expectations, and their behavioral intentions.

\subsection{Research Model Equation}

The hypotheses presented in this study investigate the direct relationships between a health resort's perceptions, expectations, and behavioral intentions, the indirect relationships between a health resort's perceptions and the behavioral intentions being mediated by expectations, and the total moderation effect of culture (as depicted in Figure 3). As a result, the present study variables can be presented in a research model equation. In Figure 3, P represents a health resort's perceptions, E represents expectations, BI represents behavioral intentions, $\mathrm{C}$ represents culture, and the slope intercepts, i.e., a1, a3, b1, b1, b2, b4, and b5.

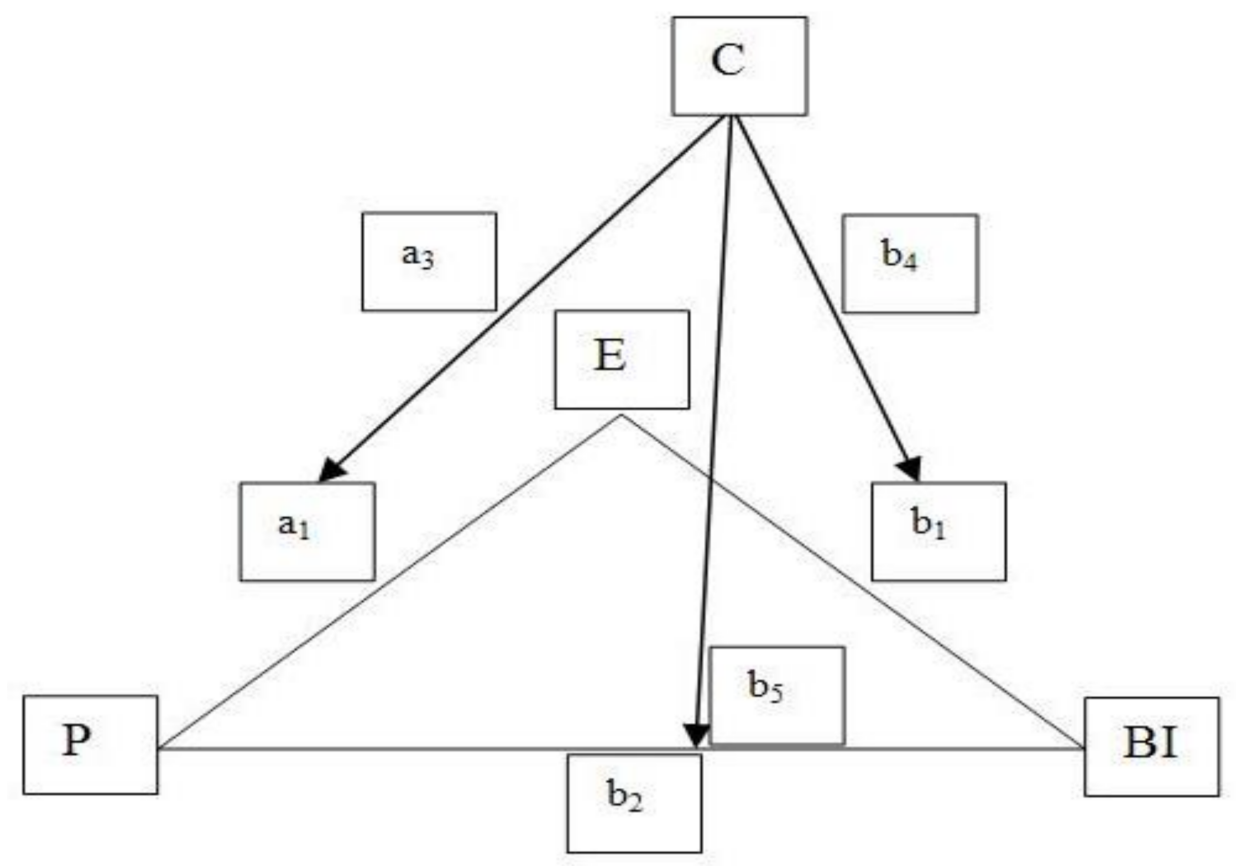

Figure 3. Total moderation construct-intercepts flow model.

The basic equation expression for the relationships between a health resort's perceptions, expectations, and behavioral intentions under cultural influence is presented below, i.e.,:

$$
\begin{gathered}
E=a_{0}+a_{1} P+a_{2} C+a_{3} P C+e_{E} \\
B I=b_{0}+b_{1} E+b_{2} P+b_{3} C+b_{4} E C+b_{5} P C+e_{B I}
\end{gathered}
$$


Substituting for E in Equation (2):

$B I=b_{0}+b_{1}\left(a_{0}+a_{1} P+a_{2} C+a_{3} P C+e_{E}\right)+b_{2} P+b_{3} C+b_{4}\left(a_{0}+a_{1} P+a_{2} C+a_{3} P C+e_{E}\right) C+b_{5} P C+e_{B I}$

Distribution and liking terms collection:

$$
\begin{gathered}
B I=b_{0}+a_{0} b_{1}+\left(b_{2}+a_{1} b_{1}\right) P+\left(b_{3}+a_{2} b_{1}+a_{0} b_{4}\right) C+a_{2} b_{4} C^{2}+\left(b_{5}+a_{3} b_{1}+a_{1} b_{4}\right) P C \\
+a_{3} b_{4} P C^{2}+e_{B I}+b_{1} e_{E}+b_{4} C e_{E}
\end{gathered}
$$

In terms of slopes:

$B I=\left[\left(b_{0}+b_{3} C\right)+\left(a_{0}+a_{2} C\right)\left(b_{1}+b_{4} C\right)\right]+\left[\left(b_{2}+b_{5} C\right)+\left(a_{1}+a_{3} C\right)\left(b_{1}+b_{4} C\right)\right] P+e_{B I}+\left(b_{1}+b_{4} C\right) e_{E}$

Hence:

$$
\begin{gathered}
{\left[\left(b_{0}+b_{3} C\right)+\left(a_{0}+a_{2} C\right)\left(b_{1}+b_{4} C\right)\right]=\text { intercepts }} \\
{\left[\left(b_{2}+b_{5} C\right)+\left(a_{1}+a_{3} C\right)\left(b_{1}+b_{4} C\right)\right]=\text { slopes }} \\
\text { direct effect first stage second stage } \\
\text { indirect effect }
\end{gathered}
$$

While:

$$
\mathrm{e}_{\mathrm{BI}}+\left(\mathrm{b}_{1}+\mathrm{b}_{4} \mathrm{C}\right) \mathrm{e}_{\mathrm{E}}=\text { residuals }
$$

\section{Methodology}

\subsection{Measurement Scale and Questionnaire}

In order to evaluate the perceived attractions of health resorts, tourists/travelers' expectations and behavioral intentions, and the impact of culture on these associations, a questionnaire was developed. There were three major sections in the survey questionnaire: a health resort's description, study variables' queries, and questions to gather demographic information. Validated measures were adopted considering various studies, that is, affordability measures were adopted from Iajevardi [6], Lee, Han, and Lockyer [67], and Wang [101]; risk-level measures were adopted from Leahy [77], Bies and Zacharia [78], Khan, Chelliah, and Haron [81], Rimal [82], Mawby et al. [83], Law [121], and Sönmez andGraefe [122]; medical facilities measures were adapted from Reddy et al. [10], Lee, Han, and Lockyer [67], Wang [101], and Safavi [123]; sustainable tourism measures were taken from Heung and Kucukusta [17], Zhang et al. [19], Han, Lee, and Hwang [69], and Mawby et al. [83]; validated measures for expectations were adopted by considering the studies of Reddy et al. [10], Shabbir, Kaufmann, and Shehzad [87], Safavi [123]; validated measures for behavioral intentions were borrowed from Reddy et al. [10], Wang [101], and Francis et al. [105]; and validated measures for culture were borrowed from Crotts and Pizam [43], An [45], and Lee and Lee [120]. However, all of the adapted measures were slightly adjusted according to the nature of the present study. Multiple items' measurement on a seven-point Likert scales from "strongly disagree" (1) to "strongly agree" (7) were utilized throughout the study for measuring variables under analysis. More precisely, a total of 16 items for the perceived attractions of visiting and experiencing a health resort's care (four items for each construct) were incorporated. Moreover, three items were included to measure expectations, and four items were included for behavioral intentions. Measurment items, which were included in the survey questionnaire, are mentioned in Table A1 (Appendix A).

A preliminary test was performed on 21 pilot samples, that is, six tourism and management instructors, six health industry professionals, and nine travelers who had prior experience of health care or medical traveling, in order to maximize the content validity of the questionnaire. The questionnaire was slightly adjusted according to the health resort's context, and improved on the basis of their 
thoroughly reviewed feedback. The questionnaire, which was originally written in the English language, was further translated into Thai, Indian, and Chinese languages, with the help of a widely applied blind translation-back translation tool. This technique was followed due to its accuracy [124]. Thai, Indian, and Chinese versions of the questionnaire were thoroughly reviewed by the respective native speakers for their clarity and understandability.

\subsection{Sampling and Data Collection}

In order to collect the data, a self-administered field survey was conducted from the second week of October 2017 to the fourth week of October 2017, through the questionnaire at two international airports in China: Beijing Capital International Airport in Beijing, and Xiamen Gaoqi International Airport in Xiamen. A convenience sampling approach was adopted in order to access the Thai, Indian, and Chinese tourists/travelers through the entry/exit points of airports. After confirming their nationality, tourists/travelers who were waiting for their flights in the lounges or waiting for their buses or pickups, and had similar understandings of visiting a health resort in terms of improvement in quality of life through health therapies, alternative treatments, T\&CM treatments, and necessary medical intervention as well as sustainable tourism opportunities, were requested to participate in the survey. The aims and goals of the study were explained to them in detail. Those travelers who voluntarily agreed to participate in the study were requested to complete the questionnaire after carefully reading and answering the survey questions. Questionnaires were handed over to the participants, and retrieved at the same location. The field survey at airports was extended to the first week of November 2017 due to a low response rate and efforts to gather an appropriate number of data samples. After three weeks of consecutive survey efforts, participants' responses led to a total of 391 completed questionnaires. After scrutinizing unusable responses, 359 responses were finally considered (including 109 Thai participants, 116 Indian participants, and 134 Chinese participants), and made part of the final data analysis. Souro [125] notes that a number of samples over 100 is suitable in order to examine results on a rating scale with a $\pm 10 \%$ margin error, hence, the present study's sample size is considered appropriate for each participating nationality sample. Among the 359 respondents, approximately $64 \%$ (230 participants) were males, and 34\% (129 participants) were females. The average age of survey participants was 38.6 years (within a range of $24-70$ years).

The survey participants' educational competence show that about $30 \%$ had school-level study, $15 \%$ mentioned themselves as undergraduates, and $54.9 \%$ described themselves as holding a graduate or a higher-level degree. About $29 \%$ mentioned their annual income was less than $\$ 25,000 ; 50.4 \%$ stated their personal annual income was between $\$ 25,001$ and $\$ 75,000$; and $14.2 \%$ mentioned their income was more than $\$ 75,000$. About $15.3 \%$ described their recent health tourism within the last six months; $58.5 \%$ stated that one to three years had passed, and $26.2 \%$ reported an experience from more than three years ago. The nationality-wise sampling characteristics are mentioned in Table 1.

Table 1. Respondents' demographics.

\begin{tabular}{|c|c|c|c|c|c|c|c|c|c|}
\hline \multirow[b]{2}{*}{ Nationality } & \multicolumn{3}{|c|}{ Thai Travelers } & \multicolumn{3}{|c|}{ Indian Travelers } & \multicolumn{3}{|c|}{ Chinese Travelers } \\
\hline & $\mathbf{N}$ & Percent & $\begin{array}{c}\text { Cumulative } \\
\text { Percent }\end{array}$ & $\mathbf{N}$ & Percent & $\begin{array}{c}\text { Cumulative } \\
\text { Percent }\end{array}$ & $\mathbf{N}$ & Percent & $\begin{array}{c}\text { Cumulative } \\
\text { Percent }\end{array}$ \\
\hline \multicolumn{10}{|l|}{ Gender } \\
\hline Males & 68 & 62.4 & 62.4 & 64 & 55.2 & 55.2 & 98 & 73.1 & 73.1 \\
\hline Females & 41 & 37.6 & 100 & 52 & 44.8 & 100 & 36 & 26.9 & 100 \\
\hline Total & 109 & 100 & & 116 & 100 & & 134 & 100 & \\
\hline Age(Average) & \multicolumn{3}{|c|}{38.2 Years } & \multicolumn{3}{|c|}{36.9 Years } & \multicolumn{3}{|c|}{38.8 years } \\
\hline \multicolumn{10}{|l|}{ Education } \\
\hline Some school study & 13 & 11.9 & 11.9 & 9 & 7.7 & 7.7 & 2 & 1.5 & 1.5 \\
\hline High school certificate & 36 & 33.0 & 44.9 & 33 & 28.4 & 36.1 & 11 & 8.3 & 9.8 \\
\hline Undergraduate & 11 & 10.0 & 54.9 & 29 & 25.0 & 61.1 & 14 & 10.4 & 20.2 \\
\hline Graduate degree & 39 & 35.9 & 90.8 & 41 & 35.4 & 96.5 & 97 & 72.3 & 92.5 \\
\hline Master degree & 8 & 7.4 & 98.2 & 4 & 3.5 & 100 & 10 & 7.5 & 100 \\
\hline Missing & 2 & 1.8 & 100 & 0 & 0 & 100 & 0 & 0 & 100 \\
\hline Total & 109 & 100 & & 116 & 100 & & 134 & 100 & \\
\hline
\end{tabular}


Table 1. Cont

\begin{tabular}{|c|c|c|c|c|c|c|c|c|c|}
\hline \multirow[b]{2}{*}{ Nationality } & \multicolumn{3}{|c|}{ Thai Travelers } & \multicolumn{3}{|c|}{ Indian Travelers } & \multicolumn{3}{|c|}{ Chinese Travelers } \\
\hline & $\mathbf{N}$ & Percent & $\begin{array}{c}\text { Cumulative } \\
\text { Percent }\end{array}$ & $\mathbf{N}$ & Percent & $\begin{array}{c}\text { Cumulative } \\
\text { Percent }\end{array}$ & $\mathbf{N}$ & Percent & $\begin{array}{c}\text { Cumulative } \\
\text { Percent }\end{array}$ \\
\hline \multicolumn{10}{|l|}{ Income (Yearly) } \\
\hline Less than $\$ 25,000$ & 47 & 43.1 & 43.1 & 28 & 24.1 & 24.1 & 29 & 21.6 & 21.6 \\
\hline$\$ 25,001-\$ 50,000$ & 34 & 31.1 & 74.2 & 41 & 35.3 & 59.4 & 37 & 27.7 & 49.3 \\
\hline$\$ 50,001-\$ 75,000$ & 15 & 13.8 & 88.0 & 21 & 18.2 & 77.6 & 33 & 24.6 & 73.9 \\
\hline$\$ 75,001-\$ 100,000$ & 6 & 5.5 & 93.5 & 10 & 8.6 & 86.2 & 13 & 9.7 & 83.6 \\
\hline$\$ 100,001$ or more & 4 & 3.7 & 97.2 & 7 & 6.0 & 92.2 & 11 & 8.2 & 91.8 \\
\hline Missing & 3 & 2.8 & 100 & 9 & 7.8 & 100 & 11 & 8.2 & 100 \\
\hline Total & 109 & 100 & & 116 & 100 & & 134 & 100 & \\
\hline \multicolumn{10}{|c|}{ Experience of health tourism recently } \\
\hline Within 6 months & 15 & 13.7 & 13.7 & 19 & 16.4 & 16.4 & 21 & 15.4 & 15.4 \\
\hline Within 1 year & 19 & 17.4 & 31.1 & 36 & 31.0 & 47.4 & 54 & 40.8 & 56.2 \\
\hline Within 2-3 years & 28 & 25.7 & 56.8 & 34 & 29.3 & 76.7 & 39 & 29.1 & 85.3 \\
\hline Within $4-5$ years & 32 & 29.5 & 86.3 & 22 & 19.0 & 95.7 & 14 & 10.3 & 95.6 \\
\hline More than 5 years & 15 & 13.7 & 100 & 5 & 4.3 & 100 & 6 & 4.4 & 100 \\
\hline Missing & 0 & 0 & 100 & 0 & 0 & 100 & 0 & 0 & 100 \\
\hline Total & 109 & 100 & & 116 & 100 & & 134 & 100 & \\
\hline $\begin{array}{l}\text { Average international } \\
\text { traveling frequency in } \\
\text { previous five (5) years }\end{array}$ & \multicolumn{3}{|c|}{5.6 times } & \multicolumn{3}{|c|}{6.9 times } & \multicolumn{3}{|c|}{7.8 times } \\
\hline
\end{tabular}

\section{Results}

\subsection{Measurement Model Results}

The loading values for the measurement model were calculated and found significant at $0.05 \%$, i.e., greater than 0.70 (Table 2). The items' level convergent validity is also shown from these results. The composite reliability values of all of the variables were found to be greater than the 0.60 cut-off levels [126], that is, they ranged from 0.824 to 0.926 , and were considered acceptable. Additionally, Cronbach's alpha values indicated a high internal consistency, i.e., above 0.70 , for all of the study constructs, and thus were found to be satisfactory [127]. Moreover, the construct-level average values were found to be greater than 0.50 , which was a threshold limit. Hence, these results support the general requirements of the model measurement. The results in Table 2 further show that each average square root of the constructs is more than the correlation of reflective items and, hence, supports the existence of discriminant validity [128]. Moreover, Table 3 shows heterotrait-monotrait (HTMT) results for all items below 0.85 or 0.90 , which is a cut-off level supporting discriminant validity [129].

Table 2. Measurement model results.

\begin{tabular}{|c|c|c|c|c|c|c|c|}
\hline Item Level Constructs & Items & LVs & $\mathrm{CR}$ & $\alpha$ & AVE & SQRT $\left(\right.$ AVE) $>$ Cor $^{2}$ & $R^{2}$ \\
\hline \multirow{2}{*}{ Affordability (A) } & A2 & 0.703 & & & & & \\
\hline & A4 & 0.837 & & & & & \\
\hline \multirow{2}{*}{ Risk Level (RL) } & RL1 & 0.842 & 0.921 & 0.836 & 0.638 & $0.798>0.603$ & \\
\hline & RL2 & 0.723 & & & & & \\
\hline \multirow{4}{*}{ Medical facilities (MF) } & MF1 & 0.812 & 0.824 & 0.773 & 0.713 & $0.741>0.609$ & \\
\hline & MF2 & 0.739 & & & & & \\
\hline & MF3 & 0.747 & & & & & \\
\hline & MF4 & 0.836 & & & & & \\
\hline Sustainable tourism (ST) & ST1 & 0.794 & 0.906 & 0.807 & 0.616 & $0.708>0.591$ & \\
\hline
\end{tabular}


Table 2. Cont.

\begin{tabular}{|c|c|c|c|c|c|c|c|}
\hline Item Level Constructs & Items & LVs & CR & $\alpha$ & AVE & SQRT (AVE) > Cor ${ }^{2}$ & $R^{2}$ \\
\hline Expectations (E) & E2 & 0.883 & & & & & \\
\hline \multirow{3}{*}{ Behavioral Intentions (BI) } & BI1 & 0.801 & 0.857 & 0.827 & 0.659 & $0.727>0.576$ & 0.742 \\
\hline & BI2 & 0.845 & & & & & \\
\hline & $\mathrm{BI} 3$ & 0.739 & & & & & \\
\hline
\end{tabular}

Note: $\mathrm{LV}=$ Loading Values; $\mathrm{AVE}=$ Average Variance Extracted; $\alpha=$ Cronbach's alpha; $\mathrm{CR}=$ Composite Reliability; $\mathrm{Cor}^{2}=$ Correlation (highest squared between model constructs); $R^{2}=$ Co-efficient of determination; Level of significance (2-tailed) $=0.05$.

Table 3. Heterotrait-monotrait (HTMT) results.

\begin{tabular}{ccccccccc}
\hline & Mean & $\begin{array}{c}\text { Standard } \\
\text { Deviation }\end{array}$ & Affordability & $\begin{array}{c}\text { Risk } \\
\text { Level }\end{array}$ & $\begin{array}{c}\text { Medical } \\
\text { Facilities }\end{array}$ & $\begin{array}{c}\text { Sustainable } \\
\text { Tourism }\end{array}$ & Expectations & $\begin{array}{c}\text { Behavioral } \\
\text { Intentions }\end{array}$ \\
\hline Affordability & 3.997 & 1.405 & 1.000 & & & & & \\
Risk Level & 4.312 & 1.213 & $0.741^{\mathrm{a}}$ & 1.000 & & & & \\
Medical facilities & 4.237 & 1.029 & 0.657 & 0.774 & 1.000 & & & \\
Sustainable tourism & 4.125 & 1.127 & 0.651 & 0.769 & 0.792 & 1.000 & 1.000 & 1.000 \\
Expectations & 3.918 & 1.311 & 0.544 & 0.564 & 0.625 & 0.604 & 0.759 & \\
Behavioral intentions & 3.724 & 1.016 & 0.453 & 0.647 & 0.647 & 0.634 & & \\
\hline \multicolumn{7}{c}{ a Correlations. }
\end{tabular}

\subsection{Structural Model Evaluation}

The endogenous variables results for the coefficients of the determination $\left(R^{2}\right)$ values were found to be over a $10 \%$ level and, hence, were noted as appropriate [129]. The $R^{2}$ for expectations (0.649) and behavioral intentions (0.742), which are presented in Table 2 and Figure 4, are considered moderate and appropriate for the present study. The results in Table 4 show $f^{2}$ and $q^{2}$ values in order to measure effect sizes. Chin [130] notes $f^{2}$ and $q^{2}$ values as 0.02 and 0.35 ; however, effect size values around 0.15 are noted as at a medium level. The results of $f^{2}$ and $q^{2}$ for the study's constructs are shown in Table 4. Moreover, the path coefficients of the structural model are calculated. A bootstrapping re-sampling method with 5000 was conducted to find the $t$-values and standard errors in tandem with each set of the bootstrap sample reporting equal observations to the basic sampling of the present study $[130,131]$, that is, 359. In the model, estimation was performed through magnitudes and signs of path coefficients in between the path relationships of the latent variables (results are summarized in Table 4 and Figure 4). The construct relationships with $p$ values and beta values in Table 4 show highly significant direct relationships among perceptions of a health resort and the behavioral intentions of tourists/travelers, that is, affordability $(\beta=0.285$ (4.473), $p=0.001)$; risk level $(\beta=0.341$ (3.284), $p=0.012)$, medical facilities $(\beta=0.246$ (3.719), $p=0.002)$, and sustainable tourism $(\beta=0.316$ (2.218), $p=0.001$ ), with behavioral intentions at a $0.05 \%$ significance level. This provides valid support to accept hypothesis H1. 


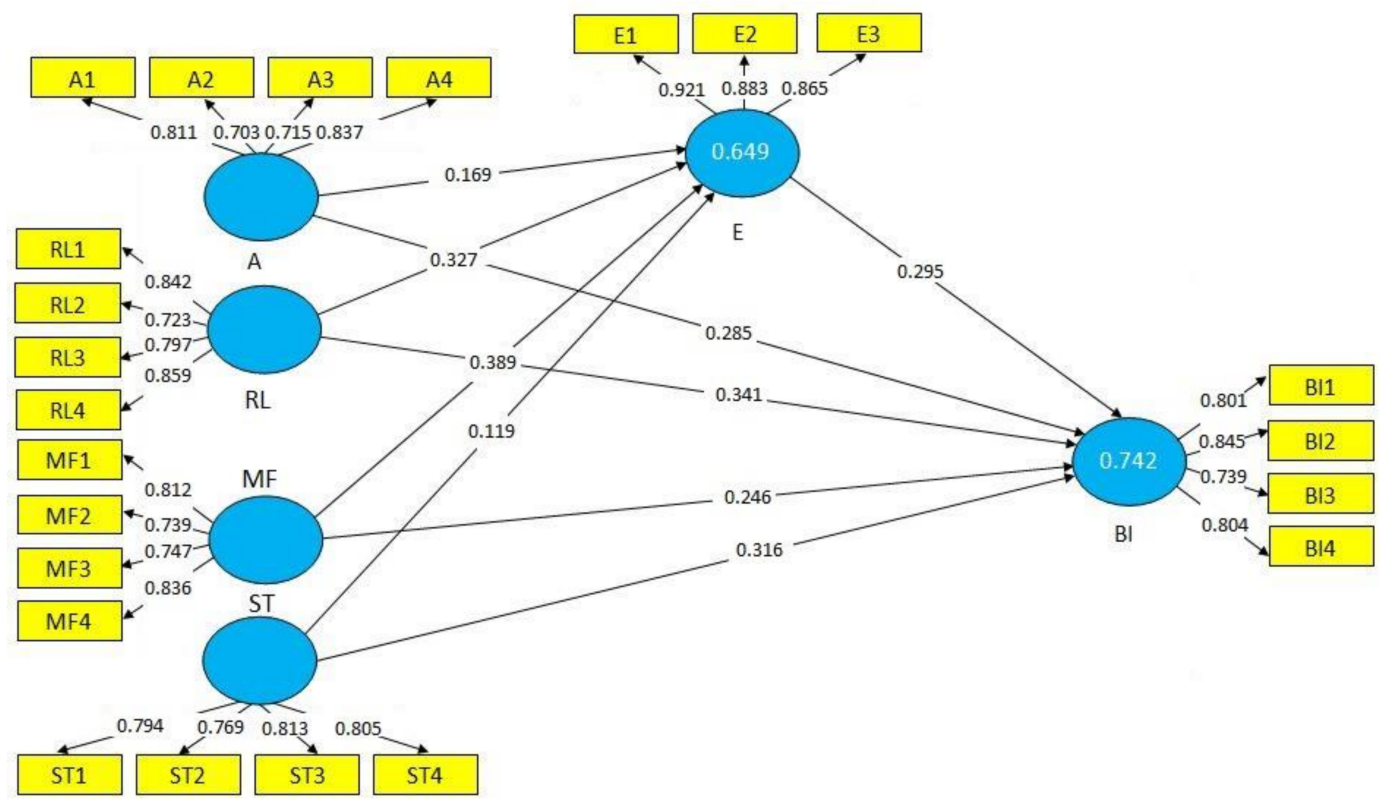

Figure 4. Structural model results.

Table 4. Structural model path coefficients (direct effect and hypothesis testing).

\begin{tabular}{cccccccc}
\hline Constructs & $\begin{array}{c}\text { Standardized } \\
\text { Coefficients }\end{array}$ & $\boldsymbol{t}$-Values & $\boldsymbol{f}^{\mathbf{2}}$ & $\boldsymbol{q}^{\mathbf{2}}$ & $\begin{array}{c}\text { Confidence } \\
\text { Interval }\end{array}$ & $\boldsymbol{p}$-Values & Results \\
\hline $\mathrm{A} \rightarrow \mathrm{BI}$ & 0.285 & 4.473 & 0.15 & 0.15 & $0.184-0.319$ & 0.001 & Hypothesis \\
$\mathrm{RL} \rightarrow \mathrm{BI}$ & 0.341 & 3.284 & 0.05 & 0.05 & $0.019-0.412$ & 0.012 & H1 Supported \\
$\mathrm{MF} \rightarrow \mathrm{BI}$ & 0.246 & 3.719 & 0.13 & 0.13 & $0.146-0.355$ & 0.002 & \\
$\mathrm{ST} \rightarrow \mathrm{BI}$ & 0.316 & 2.218 & 0.22 & 0.19 & $0.362-0.531$ & 0.001 & \\
$\mathrm{~A} \rightarrow \mathrm{E}$ & 0.169 & 4.071 & 0.07 & 0.07 & $0.153-0.306$ & 0.001 & \\
$\mathrm{RL} \rightarrow \mathrm{E}$ & 0.327 & 2.817 & 0.09 & 0.09 & $0.147-0.249$ & 0.003 & \\
$\mathrm{MF} \rightarrow \mathrm{E}$ & 0.389 & 4.126 & 0.06 & 0.06 & $0.026-0.152$ & 0.004 & \\
$\mathrm{ST} \rightarrow \mathrm{E}$ & 0.119 & 0.537 & 0.08 & 0.07 & $0.258-0.411$ & 0.000 & \\
$\mathrm{E} \rightarrow \mathrm{BI}$ & 0.295 & 3.621 & 0.03 & 0.03 & $0.033-0.147$ & 0.001 & \\
\hline
\end{tabular}

$\mathrm{A}=$ affordability, $\mathrm{BI}=$ behavioral intentions, $\mathrm{RL}=$ risk level, $\mathrm{MF}=$ medical facilities, $\mathrm{ST}=$ sustainable tourism, $\mathrm{E}=$ expectations.

\subsection{Mediation Testing}

In order to measure the mediating effect of expectations, a non-parametric bootstrapping approach was adopted [131]. The significance of association among exogenous and endogenous variables, before potential mediator inclusion, has not yet obtained mutual consensus in the literature [132]. However, the indirect impact of mediation should be significant, which purports, as documented by Hair et al. [131], its influence in absorbing some of the direct effects. The results presented in Table 5 show that the mediation/indirect relationships between affordability, risk level, medical facilities, sustainable tourism, and behavioral intentions are significant, that is $t>1.96$ at $p=0.05 \%$. The results further show that the mediation/indirect beta values absorbed some percentage of the direct beta value effects of the associated constructs, justifying mediation requirement as noted by Hair et al. [131]. Hence, the results of the mediation/indirect impact of expectations provide valid support to accept hypothesis H2. Additionally, VAF (variance account for) values were also calculated in order to examine the ratio of indirect effect size to total effect size [131], and show that the mediation/indirect impact is between $0.2 \%$ and $0.8 \%$ and, hence, interpreted as partial mediation [133]. 
Table 5. Bootstrapping mediation/indirect effect.

\begin{tabular}{|c|c|c|c|c|c|c|}
\hline $\begin{array}{c}\text { Construct } \\
\text { Effect }\end{array}$ & $\begin{array}{c}\text { Effect } \\
\text { Level-Direct } \\
(t \text {-Value })\end{array}$ & $\begin{array}{c}\text { Effect } \\
\text { Level-Indirect } \\
(t \text {-Value })\end{array}$ & $\begin{array}{c}\text { Effect } \\
\text { Level-Total }\end{array}$ & VAF & Interpretation & Results \\
\hline $\mathrm{A} \rightarrow \mathrm{E} \rightarrow \mathrm{BI}$ & $0.285(4.473)$ & $0.112(4.218)$ & 0.397 & 21.221 & $\begin{array}{c}\text { Partial } \\
\text { Mediation }\end{array}$ & \multirow{4}{*}{$\begin{array}{l}\text { Hypothesis H2 } \\
\text { Supported }\end{array}$} \\
\hline $\mathrm{RL} \rightarrow \mathrm{E} \rightarrow \mathrm{BI}$ & $0.341(3.284)$ & $0.201(2.483)$ & 0.542 & 40.472 & $\begin{array}{c}\text { Partial } \\
\text { Mediation }\end{array}$ & \\
\hline $\mathrm{MF} \rightarrow \mathrm{E} \rightarrow \mathrm{BI}$ & $0.246(3.719)$ & $0.169(3.276)$ & 0.415 & 37.138 & $\begin{array}{c}\text { Partial } \\
\text { Mediation }\end{array}$ & \\
\hline $\mathrm{ST} \rightarrow \mathrm{E} \rightarrow \mathrm{BI}$ & $0.316(2.218)$ & $0.183(1.749)$ & 0.499 & 25.339 & $\begin{array}{c}\text { Partial } \\
\text { Mediation }\end{array}$ & \\
\hline
\end{tabular}

$\mathrm{A}=$ affordability, $\mathrm{BI}=$ behavioral intentions, $\mathrm{RL}=$ risk level, $\mathrm{MF}=$ medical facilities, $\mathrm{ST}=$ sustainable tourism, $\mathrm{E}=$ expectations, $\mathrm{VAF}=$ variance accounted for; $t \mid \mathrm{N}=1.96$ at $p=0.05$ level. $80 \%$ VAF (full mediation), 20-80\% VAF (partial mediation), $<20 \%$ (no mediation) [133].

\subsection{Metric Invariance}

The metric invariance test, which is a modeling comparison, was conducted in order to testify the moderating impact of culture on Thai, Indian, and Chinese traveler groups. For this purpose, an evaluation of measurement and structural invariance models was performed [134]. The survey responses are grouped into Thai (109 cases), Indian (116 cases), and Chinese (134 cases) groups. A chi-square test was applied in order to assess measurement invariance among three traveler groups (results mentioned in Table 6). The results show that the non-restricted and full-metric invariance models did not yield a significant chi-square differential $\left(\Delta x^{2}=45.127, p>0.01\right)$. Hence, for the analysis of the responses that were received from the three groups, full-metric invariance is focused on in the next stage.

Table 6. Invariance-model statistics.

\begin{tabular}{|c|c|c|c|c|c|c|c|}
\hline & $x^{2}$ & RMSEA & $d f$ & CFI & NFI & $\Delta x^{2}$ & $\begin{array}{c}\text { Metric } \\
\text { Invariance } \\
\text { Results (Full) }\end{array}$ \\
\hline $\begin{array}{l}\text { Invariance test measurement } \\
\text { Non-restricted model }\end{array}$ & 892.164 & 0.058 & 416 & 0.917 & 0.859 & $\Delta x^{2}(26)=45.127$ & Supported \\
\hline Metric invariance (Full) & 947.831 & 0.061 & 437 & 0.908 & 0.847 & $\begin{array}{c}p>0.01 \\
\text { (insignificant) }\end{array}$ & \\
\hline Models & $x^{2}$ & RMSEA & $d f$ & \multicolumn{2}{|c|}{ CFI } & \multicolumn{2}{|c|}{ NFI } \\
\hline \multicolumn{8}{|c|}{ Invariance test (Structural) } \\
\hline $\begin{array}{l}\text { Structural (basic) modelMetric } \\
\text { invariance (full) test }\end{array}$ & 958.172 & 0.061 & 437 & \multicolumn{2}{|c|}{0.908} & \multicolumn{2}{|c|}{0.847} \\
\hline Full-path invariance model ${ }^{a}$ & 991.015 & 0.058 & 447 & \multicolumn{2}{|c|}{0.907} & \multicolumn{2}{|c|}{0842} \\
\hline \multicolumn{2}{|l|}{ Models } & \multicolumn{2}{|c|}{ Thai tourists } & \multicolumn{2}{|c|}{ Indian tourists } & \multicolumn{2}{|c|}{ Chinese tourists } \\
\hline \multirow{2}{*}{\multicolumn{2}{|c|}{$\begin{array}{l}\text { Affordability } \rightarrow \text { Expectations } \\
\text { Risk Level } \rightarrow \text { Expectations }\end{array}$}} & \multicolumn{2}{|c|}{$0.108(0.624)$} & \multicolumn{2}{|c|}{$0.099(0.476)$} & \multicolumn{2}{|c|}{$0.167(1.274)$} \\
\hline & & \multirow{2}{*}{\multicolumn{2}{|c|}{$0.183(1.997)$ * }} & \multirow{2}{*}{\multicolumn{2}{|c|}{$0.242(2.786)^{* *}$}} & \multicolumn{2}{|c|}{$0.198(2.384) *$} \\
\hline \multicolumn{2}{|c|}{ Medical facilities $\rightarrow$ Expectations } & & & & & \multicolumn{2}{|c|}{$0.824(3.511)^{* *}$} \\
\hline \multicolumn{2}{|c|}{ Sustainable tourism $\rightarrow$ Expectations } & \multicolumn{2}{|c|}{$0.629(2.915) * *$} & \multicolumn{2}{|c|}{$0.683(3.641)^{* *}$} & \multicolumn{2}{|c|}{$0.109(0.427)$} \\
\hline \multicolumn{2}{|c|}{ Affordability $\rightarrow$ Behavioral intentions } & \multicolumn{2}{|c|}{$0.171(1.142)$} & \multicolumn{2}{|c|}{$0.368(2851) * *$} & \multicolumn{2}{|c|}{$0.146(0.779)$} \\
\hline \multicolumn{2}{|c|}{ Risk Level $\rightarrow$ Behavioral intentions } & \multicolumn{2}{|c|}{$0.041(0.157)$} & \multicolumn{2}{|c|}{$0.374(2.096) *$} & \multicolumn{2}{|c|}{$0.463(2.647)^{* *}$} \\
\hline \multicolumn{2}{|c|}{ Medical facilities $\rightarrow$ Behavioral intentions } & \multicolumn{2}{|c|}{$0.029(0.107)$} & \multicolumn{2}{|c|}{$0.362(2.361) *$} & 0.689 & 5) ** \\
\hline \multicolumn{2}{|c|}{ Sustainable tourism $\rightarrow$ Behavioral intentions } & \multicolumn{2}{|c|}{$0.735(3.529) * *$} & & 99) & 0.196 & \\
\hline Expectations $\rightarrow$ Behavioral in & tions & 0.335 & )** & 0.25 & 4) ** & 0.046 & \\
\hline
\end{tabular}
$\Delta x^{2}(18)=36.941, p<0.01$ (significant); ${ }^{*} p<0.05 ;{ }^{* *} p<0.01$.

Statistical analysis differences in the study's constructs in tandem with their association among three groups were compared by testing structural invariance. The basic model of the study variables perfectly fit the data $\left(x^{2}=958.172, d f=437, p<0.001\right.$, RMSEA $\left.=0.061, \mathrm{CFI}=0.0908, \mathrm{NFI}=0.847\right)$. Meanwhile, full path variance model results were distilled as $x^{2}=991.015, d f=447, p<0.001$, RMSEA $=0.058, \mathrm{CFI}=0.907, \mathrm{NFI}=0.842$. Hence, both of these models were found to be significantly different after the comparison of the results $\left(\Delta x^{2}(18)=36.841, p<0.01\right)$. These results generally 
show that the valence of relationships among the perceived attractions of health resort, expectations, and behavioral intentions differ significantly among the Thai, Indian, and Chinese tourists within an international context (results summarized in Table 6). Thus, a significant impact of culture is found in moderating the associations among international travelers' groups and, hence, supporting the proposed hypothesis $\mathrm{H} 3$.

\section{Discussion and Implications}

This study is triggered by the research quest that, despite the boom of health tourism, little is yet known about instrumental associations among affordability, risk-bearing level, medical facilities, and sustainable tourism attractions, as well as expectations in framing the behavioral intentions of international tourists/travelers in a health resort context. These associations are important to be considered in a health resort context because of the emerging connections between T\&CM and conventional medical treatments, that is, allopathy and lifestyle treatment preferences of modern health tourists in tandem with sustainable tourism notions. The basic theme of the present study is to propose and validate a research model that is grounded in theoretical concepts and explicitly aims to understand the behavioral intentions of international tourists/travelers in order to visit a health resort for health care or other medical or quality of life improvement treatments. The primary intention is for the model to be developed by evaluating the perceptions and expectations of tourists in distinct cultural contexts. The proposed model conceptualizes the theory that tourists' intentions to visit or stay in a health resort depend on their expectations and other interlinked attractions that they are likely to perceive. Theoretical underpinnings, which are encapsulated into the present study, elucidate that tourists' expectations are the outcome of a multi-textured alignment of the perceived attractions of a health resort, and tourists' expectations significantly mediate the relationship between perceived health resorts' attractions and their behavioral intentions. The presented research model in this study claims a contribution to further developing the behavioral intentions concept of health tourists, patients, or travelers by sketching the perceived attractions of health resorts, which have hardly been studied in the literature. Moreover, an analysis and comparison of responses provided by the Thai, Indian, and Chinese travelers' groups within a health resort's conceptuality is another contribution that has been documented in the present study. This study paints some theoretical underpinnings alongside its empirical support of the canvas of health and wellness tourism in order to fuel discussions regarding the theoretical conceptualization of a health resort, which is in its infancy, in an attempt to boost research and development, and for the provision of better health services to tourists/travelers/patients. Hence, this study holds an important status in analyzing and applying the impact of international tourists' perceptions about the attractions of a health resort.

Significantly positive associations are verified through structural equation modeling (SEM) among affordability, risk level, medical facilities, sustainable tourism, expectations, and behavioral intentions. This implies that providing affordable health care, a sustainable tourism experience alongside medical facilities, and the consideration of risk levels influences the expectations of tourists/travelers, and ultimately impacts their intentions to visit a health resort. These results are in line with the work of Plehn et al. [38] in healthcare setups. Improving the health and wellness experience of tourists/travelers at the appropriate levels of their expectations could be an important consideration of health resort services' providers when defining their health resort's sustainability strategies. Health tourists may spread a positive word-of-mouth report regarding a health resort's medical treatment and their healthcare experience when they perceive that staying in a health resort is affordable, less risky, and more valuable than the other medical locations, i.e., hospitals/clinics/standalone alternative health and medical practices.

The services providers of the health industry thus need to innovate sustainable ways that can mitigate the health care concerns of health tourists, as well as promise that health care resorts are culturally affordable, less risky, in tandem with improved medical facilities, and are also sustainable tourism attractions. It will help to shape the favorable decisions of health tourists in order to experience 
a health resort's life. These efforts will bring growth in the health resort business and other interlinked industries, for example, hospitality, F\&B, restaurants, and traveling, as well as improve the welfare of the local population by providing them with a business platform.

The results of the present study underpin implied notions that the behavioral intentions of health tourists might be significantly positive when they perceive good medical facilities at a lower risk level in tandem with sustainable tourism attractions. This implied notion is the crux of this study, which purports to frame the behavioral intentions of health tourists in a health resort context. The distilled results of the present study support that the stakeholders of health resorts, that is, doctors, medical staff, therapists, hospitals, clinics, T\&CM practitioners, hotels, F\&B services providers, spa/yoga experts, traveling agents, rentals, conventional tourism services providers, etc., endeavor to improve the standards of health, medical, and wellness care by providing adequate facilities, and simultaneously meeting the expectations of health tourists/travelers/patients, which may be instrumental in achieving the favorable decisions of tourists in order to experience health resort care.

Health tourism is rapidly changing its texture, and has promised fast economic growth for participating destinations across the globe [1,2]. For successful cross-border health tourism, tourists' behaviors should be deeply understood, which may be potentially shaped by their distinct cultural norms. From this perspective, the metric invariance results of the present study are important to consider. The study results note that behavioral intentions significantly differ across Thai, Indian, and Chinese traveler groups. More precisely, the study results illuminate the relative importance of perceived attractions of a health resort in measuring international travelers' perceptions, which play a synergistic role in developing positive behavioral intentions. In-depth analysis of the structural invariance reveals that sustainable tourism attractions significantly influence Thai travelers' expectations and generate positive behavioral intentions for health resorts $\left(\beta_{\text {Sustainable tourism }} \rightarrow\right.$ Expectations $=0.629, p<0.01 ; \beta_{\text {Sustainable tourism }} \rightarrow$ Behavioral intentions $=0.735$, $p<0.01$ ); however, medical facilities (Indian travelers: $\beta_{\text {Medical facilities }} \rightarrow$ Expectations $=0.683, p<0.01$; $\beta_{\text {Medical facilities }} \rightarrow_{\text {Behavioral intentions }}=0.362, p<0.05$; Chinese travelers: $\beta_{\text {Medical facilities }} \rightarrow$ Expectations $\left.=0.824, p<0.01 ; \beta_{\text {Medical facilities }} \rightarrow_{\text {Behavioral intentions }}=0.689, p<0.01\right)$, in tandem with risk level (Indian travelers: $\beta_{\text {Risk level }} \rightarrow_{\text {Expectations }}=0.242, p<0.01 ; \beta_{\text {Risk level }} \rightarrow$ Behavioral intentions $=0.344$, $p<0.05$; Chinese travelers: $\beta_{\text {Risk level }} \rightarrow_{\text {Expectations }}=0.198, p<0.05$; $\beta_{\text {Risk level }} \rightarrow_{\text {Behavioral intentions }}=$ $0.463, p<0.01)$ are found to be significantly influencing Indian and Chinese respondents' behaviors regarding visiting health resorts. However, it is important to mention that medical facilities are considered comparatively more important than the other perceived attractions of health resorts among the three groups of international travelers. This implied notion underpins the need to deliver quality medical treatments, health services, and the competent availability of doctors, paramedical staff, pharmacists, T\&CM practitioners, and post-operative care services in order to meet the expectations of health tourist/travelers or patients. Additionally, medical/wellness attractions, for example, medical and thermal baths, medical caves, climatic resorts, medical gas baths, therapeutic gymnastics etc., will certainly motivate Thai, Indian, and Chinese health tourists to avail health care in a health resort. Hence, a cross-cultural influence is evident from the analysis of this study, and the results are in line with the discussions made by Kang et al. [42] and An et al. [45].

Despite massive cross-border movements of health tourists, sophisticated research grounds do not yet succinctly note cross-cultural traveling behaviors. The present study's findings will serve academics and professionals of the health, medical, wellness, and tourism industries in order to better conceptualize the impact of culture on health tourists' perceptions and their ultimate decision-making for availing health care. Moreover, the findings of the present study can help health resorts' marketers with developing innovative strategies in order to grab the attention of Thai, Indian, and Chinese health tourists (for example, cross-cultural marketing and advertising). The results may also help retain them as their loyal customers, and may further be applied to other tourists/travelers belonging to different nationalities. In order to meet the needs and expectations of Thai international travelers, health resorts' professionals need to focus on improving sustainable tourism attractions (i.e., clean environment, 
hygienic health care facilities, clean water, therapeutic landscapes, as well as the development of scenic tourism attractions, that is, beaches, flora and fauna, wildlife, parks, etc. These sustainable tourism attractions can be developed in tandem with developing other tourism attractions, for example, cultural: historical buildings, museums, and religious institutions, etc.; traditions: folklore, handicrafts, and music, etc.; and entertainment: cinemas, zoos, nightlife, and cuisine, etc. The present study's results show the underlining phenomena of health tourists' expectations and their behavioral intentions by analyzing the perceived attractions in a health resort infrastructure. Nevertheless, deeper research efforts are further recommended in order to generalize the discussed results of the present study to a broader canvas of tourism with sustainability and health premises.

\section{Limitations}

There are several limitations in the present study that should be taken into consideration while developing future research. Field surveys were conducted at international airport locations in two cities in China. The response of international health tourists/travelers may be different in different settings, for example, tourism sites, medical clinics, hospitals, etc., which could be in other geographic locations. A wider and diversified sampling may be better in order to achieve external validity and reduce limitations in sampling. Moreover, all of the attributes of a health resort's attractions that may influence health tourists' expectations and their behavioral intentions were not incorporated in the proposed research model. Future research may consider other attractions of health resorts, such as for example, a specialized medical lodging facility near health resorts, a medical restaurant preparing special food in order to meet the expectations of tourists/travelers/patients for their health and wellness, a dedicated medical gymnasium, cosmetic clinics in order to meet beauty enhancement desires, etc. Additional attraction constructs in the proposed research model will further solidify understanding of the behavioral intentions of health tourists. The present study was conducted on three countries' participants, that is, Thailand, India, and China. The response of participants might be different in other countries due to their different cultural norms. Hence, it is recommended to deal with the results of the study cautiously while generalizing it in other countries, because national culture might have its own distinct impact on individuals' responses.

\section{Conclusions}

The major challenging frontier for the academics and professionals of health tourism is the development of innovative thoughts in order to read and shape the positive behavioral intentions of health tourists, and attract them towards their services. By adopting a theoretical concept development approach as a basic launching platform, the present study helps the stakeholders of the health industry with its empirical evidences espousing cultural influence in order to understand health tourists' behavior in the context of a health resort. In this study, complex relationships between the perceived attractions of a health resort, health tourists' expectations, and their behavioral intentions are woven into distinct cultural influence. Generally, the study emphasizes developing deeper and broader associations among the stakeholders of health, medical, wellness, and sustainable tourism industries, which merge in health resorts in order to deliver a satisfied health care experience, and understanding the unique cultural norms of international tourists/travelers/patients, in order to expect high profits for their services. This study has taken a sophisticated approach in defining the infant concept of the health resort through its theoretical underpinnings, and the likely perceptions of health tourists on empirical grounds, which provides a stable platform for future research and development in a health resort context and other interlinked setups.

Acknowledgments: We acknowledge the cooperation of graduate students of University of Science and Technology Beijing and the graduate students of Xiamen University in helping the authors to conduct field surveys. This research work is supported by National Natural Science Foundation of China under project grant\# 71572039.This research is also supported by Innovation Team Project of Philosophy and Social Science of Fuzhou University under project grant\# 17TD06. The sponsors have no role in the collection, analysis and interpretation of data; in the writing of the report; and in the decision to submit the article for publication. 
Author Contributions: Salman Majeed, Changbao Lu, and Mahwash Majeed conceived the research project and designed the experiments. Salman Majeed and Changbao Lu performed the experiments. Salman Majeed and Muahmmad Naeem Shahid analayed the data. Mahwash Majeed and Muahmmad Naeem Shahid contributed with revisions and proofreading. Salman Majeed and Mahwash Majeed wrote the paper.

Conflicts of Interest: The authors declare no conflict of interest.

\section{Appendix A Items Measurement}

From scale 1 to 7 indicates whether you disagree or agree with the statements. Please tick the number based on your opinion of each statement below.

To stay in a health resort while traveling internationally for health/medical/wellness treatments will help.

Table A1. Survey questionnaire items.

\begin{tabular}{|c|c|c|c|c|c|c|c|c|}
\hline \multirow{3}{*}{ No } & \multirow[b]{3}{*}{ Affordability } & \multicolumn{7}{|c|}{ Agreement } \\
\hline & & \multicolumn{4}{|c|}{ Strongly Disagree- } & \multicolumn{3}{|c|}{$\longrightarrow$ Strongly Agree } \\
\hline & & $\begin{array}{l}\text { Strongly } \\
\text { Disagree }\end{array}$ & Disagree & $\begin{array}{l}\text { Somewhat } \\
\text { Disagree }\end{array}$ & Neutral & $\begin{array}{l}\text { Somewhat } \\
\text { Agree }\end{array}$ & Agree & $\begin{array}{c}\text { Strongly } \\
\text { Agree }\end{array}$ \\
\hline 1 & $\begin{array}{l}\text { To save the time/effort required to access different } \\
\text { medical/healthcare/aesthetic services and lodging facility. }\end{array}$ & 1 & 2 & 3 & 4 & 5 & 6 & 7 \\
\hline 2 & $\begin{array}{l}\text { To find my preferred healthcare/medical treatment } \\
\text { economically than other healthcare/medical settings. }\end{array}$ & 1 & 2 & 3 & 4 & 5 & 6 & 7 \\
\hline 3 & To travel easily from my country at a lower cost. & 1 & 2 & 3 & 4 & 5 & 6 & 7 \\
\hline 4 & $\begin{array}{l}\text { To avail health/medical/wellness services with favorable } \\
\text { exchange rates. }\end{array}$ & 1 & 2 & 3 & 4 & 5 & 6 & 7 \\
\hline \multicolumn{9}{|c|}{ Risk Level } \\
\hline 5 & $\begin{array}{l}\text { To avoid the risk that the intended healthcare/medical } \\
\text { treatment will not produce the desired results as expected. }\end{array}$ & 1 & 2 & 3 & 4 & 5 & 6 & 7 \\
\hline 6 & $\begin{array}{l}\text { To avoid the risk that existing health condition will be worst } \\
\text { if I travel to another destination. }\end{array}$ & 1 & 2 & 3 & 4 & 5 & 6 & 7 \\
\hline 7 & $\begin{array}{l}\text { To avoid the risk that my healthcare expenses, overall, will } \\
\text { not benefit with good savings. }\end{array}$ & 1 & 2 & 3 & 4 & 5 & 6 & 7 \\
\hline 8 & To avoid the risk of accidental injury or any kind of danger. & 1 & 2 & 3 & 4 & 5 & 6 & 7 \\
\hline \multicolumn{9}{|c|}{ Medical Facilities } \\
\hline 9 & To find technically advanced medical facilities. & 1 & 2 & 3 & 4 & 5 & 6 & 7 \\
\hline 10 & $\begin{array}{l}\text { To find aesthetic services (e.g., alternative treatments, diet } \\
\text { and exercise plan etc.). }\end{array}$ & 1 & 2 & 3 & 4 & 5 & 6 & 7 \\
\hline 11 & $\begin{array}{l}\text { To find a quality post-operative care with privacy and } \\
\text { confidentiality. }\end{array}$ & 1 & 2 & 3 & 4 & 5 & 6 & 7 \\
\hline 12 & To find the services of qualified medical staff. & 1 & 2 & 3 & 4 & 5 & 6 & 7 \\
\hline \multicolumn{9}{|c|}{ Sustainable Tourism } \\
\hline 13 & $\begin{array}{l}\text { To relax mentally and physically in non-polluted/less } \\
\text { polluted sites }\end{array}$ & 1 & 2 & 3 & 4 & 5 & 6 & 7 \\
\hline 14 & To experience the beauty of nature, e.g., beaches, and fun. & 1 & 2 & 3 & 4 & 5 & 6 & 7 \\
\hline 15 & $\begin{array}{l}\text { To find a package that offers healthcare/medical treatment } \\
\text { and tourism adventure to lodging with good meal. }\end{array}$ & 1 & 2 & 3 & 4 & 5 & 6 & 7 \\
\hline 16 & To find the feeling of well-being to me. & 1 & 2 & 3 & 4 & 5 & 6 & 7 \\
\hline \multicolumn{9}{|c|}{ Expectations } \\
\hline 17 & $\begin{array}{l}\text { I feel that a health resort will help me with a good } \\
\text { health/medical/tourism experience. }\end{array}$ & 1 & 2 & 3 & 4 & 5 & 6 & 7 \\
\hline 18 & $\begin{array}{l}\text { A health resort would provide better medical/healthcare } \\
\text { care than I expect. }\end{array}$ & 1 & 2 & 3 & 4 & 5 & 6 & 7 \\
\hline 19 & $\begin{array}{l}\text { I feel a health resort will offer a valuable care than the care } \\
\text { available in other healthcare/medical locations/hospitals etc. }\end{array}$ & 1 & 2 & 3 & 4 & 5 & 6 & 7 \\
\hline \multicolumn{9}{|c|}{ Behavioral intentions } \\
\hline 20 & $\begin{array}{l}\text { I will prefer to visit a health resort while traveling in another } \\
\text { country for health care and medical treatment. }\end{array}$ & 1 & 2 & 3 & 4 & 5 & 6 & 7 \\
\hline 21 & $\begin{array}{l}\text { I will prefer a health resort for my healthcare and medical } \\
\text { treatment. }\end{array}$ & 1 & 2 & 3 & 4 & 5 & 6 & 7 \\
\hline 22 & I will tell others about my experience in the health resort. & 1 & 2 & 3 & 4 & 5 & 6 & 7 \\
\hline 23 & $\begin{array}{l}\text { I will prefer to find my health treatments in health resort than } \\
\text { stand alone facilities. }\end{array}$ & 1 & 2 & 3 & 4 & 5 & 6 & 7 \\
\hline
\end{tabular}




\section{References}

1. Majeed, S.; Lu, C. Changing preferences, moving places and third party administrators: A scoping review of medical tourism trends (1990-2016). Almatourism 2017, 15, 56-83.

2. Majeed, S.; Lu, C.; Tariq, J. The journey from an allopathic to natural treatment approach: A scoping review of medical tourism and health systems. Eur. J. Integr. Med. 2017, 16, 22-32. [CrossRef]

3. Kovacs, E.; Szocska, G.; Knai, C. International Patients on operation vacation-Perspectives of patients travelling to Hungary for Orthopaedic treatments. Int. J. Health Policy Manag. 2014, 3, 333-340. [CrossRef] [PubMed]

4. Makinde, O.A. Physicians as medical tourism facilitators in Nigeria: Ethical issues of the practice. Croat. Med. J. 2016, 56, 601-604. [CrossRef]

5. Scott, S. Many tourists are having medical procedures done in other countries other than their own. J. Tour. Hosp. 2016, 5, 231. [CrossRef]

6. Iajevardi, M. A Comprehensive Perspective on Medical Tourism Context and Create a Conceptual Framework. J. Tour. Hosp. 2016, 5, 236. [CrossRef]

7. George, B.P.; Henthorne, T.L. The incorporation of telemedicine with medical tourism: A study of consequences. J. Hosp. Mark. Manag. 2009, 18, 512-522. [CrossRef]

8. Bookman, M.Z.; Bookman, K.R. Medical Tourism in Developing Countries; Palgrave Macmillan: New York, NY, USA, 2007.

9. Amouzagar, S.; Mojaradi, Z.; Izanloo, A.; Beikzadeh, S.; Milani, M. Qualitative Examination of Health Tourism and its Challenges. Int. J. Travel Med. Glob. Health 2016, 4, 88-91. [CrossRef]

10. Reddy, S.G.; York, V.K.; Brannon, L.A. Travel for treatment: Students' perspective on medical tourism. Int. J. Tour. Res. 2010, 12, 510-522. [CrossRef]

11. Sharafuddin, M.A. Sidha and Wellness Tourism: Opportunities and Challenges For "Brand Tamilnadu". Int. J. Res. Ayurveda Pharm. 2015, 6, 387-394. [CrossRef]

12. Yeoh, E.; Othman, K.; Ahmad, H. Understanding medical tourists: Word-of-mouth and viral marketing as potent marketing tools. Tour. Manag. 2013, 34, 196-201. [CrossRef]

13. Heung, V.C.; Kucukusta, D.; Song, H. A conceptual Model for Medical tourism: Implications for future research. J. Travel Tour. Mark. 2010, 27, 236-251. [CrossRef]

14. Reisman, D. Trade in Health, Economics, Ethics and Public Policy; Edward Elgar: Cheltenham, UK, 2014.

15. Manhas, P.S.; Ramjit, K. Marketing analysis of Medical Tourism in India. Enlight. Tour. Pathmak. J. 2015, 5, 1-39.

16. Hanefeld, J.; Horsfall, D.; Lunt, N.; Smith, R. Medical tourism: A cost or benefit to the NHS? PLoS ONE 2013, 8, e70406. [CrossRef] [PubMed]

17. Heung, V.C.; Kucukusta, D. Wellness Tourism in China: Resources, Development and Marketing. Int. J. Tour. Res. 2013, 15, 346-359. [CrossRef]

18. Smith, M.K.; Puczkó, L. More than a special interest: Defining and determining the demand for health tourism. Tour. Recreat. Res. 2015, 40, 205-219. [CrossRef]

19. Zhang, A.; Zhong, L.; Xu, Y.; Wang, H.; Dang, L. Tourists' perception of haze pollution and the potential impacts on travel: Reshaping the features of tourism seasonality in Beijing, China. Sustainability 2015, 7, 2397-2414. [CrossRef]

20. Vetitnev, A.; Dzubina, A. Spa-services and sanatorium-resort complexes of Russia. Tourism 2013, 61, $187-200$.

21. Hall, C.M. Health and medical tourism: A kill or cure for global public health? Tour. Rev. 2011, 66, 4-15. [CrossRef]

22. Connell, J. Medical tourism: Sea, sun, sand and ... surgery. Tour. Manag. 2006, 27, 1093-1100. [CrossRef]

23. Turner, L. Medical tourism: Family medicine and international health-related travel. Can. Fam. Physician 2007, 53, 1639-1641. [PubMed]

24. Evans, J.D.; Crooks, V.A. Kingsbury, P.T. Theoretical injectiions: On the therapeutic aesthetics of medical spaces. Soc. Sci. Med. 2009, 69, 716-721. [CrossRef] [PubMed]

25. Buzinde, C.N.; Yarnal, C. Theoretical landscapes and postcolonial theory: A theoretical approach to medical tourism. Soc. Sci. Med. 2012, 74, 783-787. [CrossRef] [PubMed]

26. Anischenko, E.A.; Stas, N.T.; Churáňov, A.B.; Tenova, Z.Y.; Chakarova, L.H. Resort Complex of the Russian Federation: Modern Aspect of Development. Int. J. Econ. Financ. Issues 2016, 6, 139-144. 
27. Bennett, M.; King, B.; Milner, L. The health resort sector in Australia: A positioning study. J. Vacat. Mark. 2004, 10, 122-137. [CrossRef]

28. Horowitz, M.D.; Rosensweig, J.A. Medical tourism-Health care in the global economy. Physician Exec. 2007, 33, 24-30. [PubMed]

29. Azadi, F.; Maleki, M.; Tabibi, S.J.; Azmal, M. A Medical Tourist Perception of Iranian Hospital Quality: Limited Employee Foreign Language Skills Negatively Impact Communication. Int. J. Hosp. Res. 2012, 1, 85-90.

30. Cohen, I.G. Patients with Passports: Medical Touirms, Law, and Ethics; Oxford University Press: New York, NY, USA, 2014.

31. Heung, V.C.; Kucukusta, D.; Song, H. Medical tourism developement in Hongkong: An assssment of the barriers. Tour. Manag. 2011, 32, 995-1005. [CrossRef]

32. Voigt, C.; Brown, G.; Howat, G. Wellness tourists: In search of transformation. Tour. Rev. 2011, 66, 16-30. [CrossRef]

33. Ferguson, R.J.; Paulin, M.; Pigeassou, C.; Gauduchon, R. Assessing service management effectiveness in a health resort: Implications of technical and functional quality. Manag. Serv. Qual. 1999, 9, 58-65. [CrossRef]

34. Smith, M.; Kelly, C. Holistic tourism: Journeys of the self? Tour. Recreat. Res. 2006, 31, 15-24. [CrossRef]

35. Chen, K.-H.; Chang, F.-H.; Wu, C. Investigating the wellness tourism factors in hot spring hotel customer service. Int. J. Contemp. Hosp. Manag. 2013, 25, 1092-1114. [CrossRef]

36. Wu, H.L.; Liu, C.H.; Hsu, W.H. An integrative model of consumers' perceptions of health care services in Taiwan. Serv. Ind. J. 2008, 29, 1307-1319. [CrossRef]

37. Sarwar, A.A.; Manaf, N.A.; Omar, A. Medical Tourist's Perception in Selecting their Destination: A Global Perspective. Iran. J. Public Health 2012, 41, 1-7. [PubMed]

38. Plehn, N.; Folkert, L.; Meissner, A.; Plehn, G. Expectations of Russian medical tourists on German health care services: A Kano model-based analysis. J. Tour. Hosp. 2016, 5, 208. [CrossRef]

39. Chou, S.Y.; Kiser, A.I.T.; Rodriguez, E.L. An expectation confirmation perspective of medical tourism. J. Serv. Sci. Res. 2012, 4, 299-318. [CrossRef]

40. Černikovaite, M.E.; Mameniškis, M.J. Medical tourists' expectations when choosing Lithuania for health care services. Soc. Transform. Contemp. Soc. 2015, 3, 24-39.

41. Lee, F. If Disney Ran Your Hospital: $9 \frac{1}{2}$ Things You Would Do Differently; Second River Healthcare Press: Bozeman, MT, USA, 2004.

42. Kang, M.; Moscardo, G. Exploring Cross-cultural Differences in Attitudes towards Responsible Tourist Behavior: A comparison of Korean, British and Australian Tourists. Asia Pac. J. Tour. Res. 2007, 11, 303-320. [CrossRef]

43. Crotts, J.C.; Pizam, A. The effect of national culture on consumers' evaluation of travel services. J. Tour. Cult. Commun. 2003, 4, 17-28. [CrossRef]

44. Connell, J. Contemporary Medical Tourism: Conceptualisation, Culture and Commodification. Tour. Manag. 2013, 34, 1-13. [CrossRef]

45. An, D. Understanding Medical Tourists in Korea: Cross-Cultural Perceptions of Medical Tourism among Patients from the USA, Russia, Japan, and China. Asia Pac. J. Tour. Res. 2014, 19, 1141-1169. [CrossRef]

46. Bartoluci, M.; Hendija, Z. Investment management in Croatian Health Tourism. J. Account. Manag. 2012, 2, 70-78.

47. Marlowe, J.; Sullivan, P. Medical Tourism: The Ultimate Outsourcing. HR Hum. Resour. Plan. 2007, 30, 8-10.

48. Mason, A.; Wright, K.B. Framing Medical Tourism: An Examination of Appeal, Risk, Convalescence, Accreditation, and Interactivity in Medical Tourism Web Sites. J. Health Commun. 2011, 16, 163-177. [CrossRef] [PubMed]

49. Ramirez de Arellano, A.B. Patients Without borders: The emergence of medical tourism. Int. J. Health Serv. Plan. Adm. Eval. 2007, 37, 193-198. [CrossRef] [PubMed]

50. Centran, M.; DeMicco, F.; Davies, O. Hospitality 2015: The Future of Hospitality and Travel; American Hotel \& Lodging Institute: Lansing, MI, USA, 2010.

51. Ellis, S. Are Wellness and Medical Tourism Industries Two Different Topics? Available online: https:/ / www.imtj.com/articles/are-wellness-and-medical-tourism-industries-two-different-topics / (accessed on 26 March 2018). 
52. Hall, C.M. Medical Tourism: The Ethics, Regulation, and Marketing of Health Mobility; Routledge: London, UK, 2013.

53. Smith, M.K.; Puczkó, L. Health, Tourism and Hospitality: Spas, Wellness and Medical Travel; Routledge: London, UK, 2013.

54. García-Altés, A. The Development of Health Tourism Services. Ann. Tour. Res. 2005, 32, 262-266. [CrossRef]

55. Kušen, E. Positioning medical tourism in the broader framework of health tourism. Tourism 2011, 59, 95-99.

56. Smith, C.; Jenner, P. Health tourism in Europe. Travel Tour. Anal. 2000, 1, 41-59.

57. Yang, Y.-T.; Al-Ani, S.; Bartlett, G.; Moazzam, A. PR29P cosmetic medical tourism: Its true cost. ANZ J. Surg. 2009, 79, 60. [CrossRef]

58. Goeldner, C. 39th Congress AIEST: English workshop summary. Rev. Tour. 1989, 44, 6-7.

59. Carrera, P.; Bridges, J. Globalization and healthcare: Understanding health and medical tourism. Rev. Pharmacoecon. Outcomes Res. 2006, 6, 447-454. [CrossRef] [PubMed]

60. Hunter-Jones, P. Cancer and tourism. Ann. Tour. Res. 2004, 32, 70-92. [CrossRef]

61. Jankovic, S.; Persic, M. Reporting standards for health resort-Assumption for successful benchmarking. In Proceedings of the 7th International Scientific Conference on Economic and Social Development, New York, NY, USA, 24 October 2014; pp. 334-365.

62. Gutenbrunner, C.; Bender, T.; Cantista, P.; Karagülle, Z. A proposal for a worldwide definition of health resort medicine, balneology, medical hydrology and climatology. Int. J. Biiometeorol. 2010, 54, 495-507. [CrossRef] [PubMed]

63. Konu, H.; Tuohino, A.; Björk, P. Well-being tourism in Finland. In Health, Tourism and Hospitality: Spas, Wellness and Medical Travel; Smith, M.K., Puczkó, L., Eds.; Routledge: London, UK, 2013; pp. 345-349.

64. Tsymbal, N. Overview of Wellness Tourism in Russia. 2014. Available online: http://www. globalwellnesssummit.com/images/stories/gsws2014/pdf/Overview_of_Wellness_Tourism_in_ Russia.pdf (accessed on 30 December 2016).

65. Vrkljan, S.; Hendija, Z. Business performance of health tourism service providers in the republic of Croatia. Acta Clin. Croat. 2016, 55, 79-86. [CrossRef] [PubMed]

66. Vittal, P.C.; Subhash, A.P.; Sharma, B.R.; Ramachandran, M. Emerging trends and future prospects of medical tourism in India. Indian J. Pharm. Sci. Res. 2015, 7, 246-251.

67. Lee, M.; Han, H.; Lockyer, T. Medical tourism-attracting Japanese tourists for medical tourism experience. J. Travel Tour. Mark. 2012, 29, 69-86. [CrossRef]

68. Müeller, H.; Kaufmann, E.L. Wellness tourism: Market analysis of a special health tourism segment and implications of the hotel industry. J. Vacat. Mark. 2001, 7, 5-17. [CrossRef]

69. Han, J.H.; Lee, M.L.; Hwang, Y.-S. Tourists' environmentally responsible behavior in response to climate change and tourist experience in nature-based tourism. Sustainability 2016, 8, 644. [CrossRef]

70. Docrates. Health Care Hotel Helsinki. 2012. Available online: http://www.docrates.com/en/docrateshospital/health-care-hotel-helsinki (accessed on 24 March 2017).

71. Cormany, D.; Baloglu, S. Medical Travel Facilitator Websites: An Exploratory Study of Web Page Contents and Services Offered to the Prospective Medical Tourist. Tour. Manag. 2010, 32, 709-716. [CrossRef]

72. Skar, M.; Odden, A.; Vistad, O.I. Motivation for mountain biking in Norway: Change and Stability in late-modern outdoor recreation. Nor. J. Geogr. 2008, 62, 36-45. [CrossRef]

73. Pan, S.; Ryan, C. Mountain Areas and Visitor usage-Motivations and Determinants of Satisfaction: The Case of Pirongia Forest Park, New Zealand. J. Sustain. Tour. 2007, 15, 288-308. [CrossRef]

74. Sultana, S.; Haque, A.; Momen, A.; Yasmin, F. Factors Affecting the Attractiveness of Medical Tourism Destination: An Empirical Study on India. Iran. J. Public Health 2014, 43, 867-876. [PubMed]

75. Bieger, T.; Laesser, C. Information Source for Travel Decisions: Toward a source process model. J. Travel Res. 2004, 42, 357-371. [CrossRef]

76. Mitchell, V.W.; Vassos, V. Perceived risk and risk reduction in holiday purchases: A cross-cultural and gender analysis. J. Euro-Mark. 1997, 6, 47-79. [CrossRef]

77. Leahy, A.L. Medical Tourism: The Impact of Travel to Foreign Countries for Healthcare. Surgeon 2008, 6, 260-261. [CrossRef]

78. Bies, W.; Zacharia, L. Medical Tourism: Outsourcing Surgery. Math. Comput. Model. 2007, 46, 1144-1159. [CrossRef] 
79. Turner, L. 'First World Health Care at Third World Prices': Globalization, Bioethics and Medical Tourism. BioSocieties 2007, 2, 303-325. [CrossRef]

80. Lunt, N.; Hardey, M.; Mannion, R. Nip, Tuck and Click: Medical Tourism and the Emergence of Web-Basaed Health Information. Open Med. Inform. J. 2010, 4, 1-11. [CrossRef] [PubMed]

81. Khan, M.J.; Chelliah, S.; Haron, M.S. Medical Tourism Destination Image Formation Process: A Conceptual Model. Int. J. Healthc. Manag. 2016, 9, 134-143. [CrossRef]

82. Rimal, R.N. Perceived Risk and Self-Efficacy as Motivators: Understanding Individuals' Long-Term Use of Health Information. J. Commun. 2001, 51, 633-654. [CrossRef]

83. Mawby, R.I.; Tecău, A.S.; Constantin, C.P.; Chitu, I.B.; Tescasiu, B.T. Addressing the Security Concerns of Locals and Visitors for the Sustainable Development of Tourist Destinations. Sustainability 2016, 8, 524. [CrossRef]

84. Ruka, E.; Garel, P. Medical Tourism; Hope Publications: Brussels, Belgium, 2015.

85. Ruan, W.-Q.; Li, Y.-Q.; Liu, C.-H.S. Measuring tourism risk impacts on destination image. Sustainability 2017, 9, 1501. [CrossRef]

86. Pizam, A.; Ellis, T. Customer satisfaction and its measurement in hospitality enterprise. Int. J. Contemp. Hosp. Manag. 1999, 11, 326-339. [CrossRef]

87. Shabbir, S.; Kaufmann, H.; Shehzad, M. Service Quality, Word of Mouth and Trust: Drivers to Achieve Patient Satisfaction'. Sci. Res. Essay 2010, 5, 2457-2462.

88. Zineldin, M. The Quality of Health Care and Patient Satisfaction. Int. J. Health Care Qual. Assur. 2006, 19, 60-92. [CrossRef]

89. Oliver, R.L. Effect of Expectation and Disconfirmation on Post Exposure Product Evaluations: An Alternative Interpretation'. J. Appl. Psychol. 1997, 62, 480-486. [CrossRef]

90. Spreng, R.A.; MacKenzie, S.B.; Olshavsky, R.W. A reexamination of the determinants of consumer satisfaction. J. Mark. 1996, 60, 15-26. [CrossRef]

91. Casanova, E.M.; Sutton, B. Transnational Body Projects: Media Representations of Cosmetic Surgery Tourism in Argentina and the United States. Am. Sociol. Assoc. 2013, 19, 57-81. [CrossRef]

92. Holliday, R.; Bell, D.; Hardy, K.; Hunter, E.; Jones, M.; Probyn, E.; Taylor, J.S. Beautiful Face, Beautiful space: Relational Geographies and Gender in Cosmetic Surgery Tourism Websites. Gend. Place Cult. 2015, 22, 90-106. [CrossRef]

93. Viladrich, A.; Baron-Faust, R. Medical tourism in tango Paradise: The internet branding of cosmetic surgery in Argentina. Ann. Tour. Res. 2014, 45, 116-131. [CrossRef]

94. Yang, C.C. The Establishment of a TQM System for the Health Care Industry. TQM Mag. 2003, 15, 93-98. [CrossRef]

95. Jaapar, M.; Musa, G.; Moghavvemi, S.; Saub, R. Dental Tourism: Examining tourist profiles, motivation and satisfaction. Tour. Manag. 2017, 61, 538-552. [CrossRef]

96. Bennett, J.K.; Fuertes, J.N.; Keitel, M.; Phillips, R. The role of patient attachment and working alliance on patient adherence, satisfaction, and health-related quality of life in lupus treatment. Patient Educ. Couns. 2011, 85, 53-59. [CrossRef] [PubMed]

97. Sirakaya, E.; Woodside, A.G. Building and Testing Theories of Decision Making by Travelers. Tour. Manag. 2005, 26, 815-831. [CrossRef]

98. Ajzen, I.; Fishbein, M. Understanding Attitudes and Predicting Social Behaviour; Prentice-Hall: Englewood Cliffs, NJ, USA, 1980.

99. Ajzen, I. From Intentions to Actions: A Theory of Planned Behavior. In Action-Control: From Cognition to Behavior; Kuhl, J., Beckmann, J., Eds.; Springer: Heidelberg, Germany, 1985; pp. 11-39.

100. Ajzen, I. The Theory of Planned Behavior. Organ. Behav. Hum. Decis. Process. 1991, 50, 179-211. [CrossRef]

101. Wang, H.Y. Value as a Medical Tourism Driver. Manag. Serv. Qual. 2012, 22, 465-491. [CrossRef]

102. Quintal, V.A.; Lee, J.A.; Soutar, G.N. Risk, uncertainity and the theory of planned behavior: A tourism example. Tour. Manag. 2010, 31, 797-805. [CrossRef]

103. Parson, J.T.; Siegel, A.W.; Cousin, J.H. Late Adolescent Risk-Taking: Effects of Perceived Benefits and Perceived Risks on Behavioral Intentions and Behavioral Change. J. Adolesc. 1997, 20, 381-392. [CrossRef] [PubMed]

104. Ajzen, I. Attitudes, Personality, and Behaviour; Dorsey: Chicago, IL, USA, 1988. 
105. Francis, J.J.; Eccles, M.P.; Johnston, M.; Walker, A.; Grimshaw, J.; Foy, R.; Kaner, E.F.S.; Smith, L.; Bonetti, D. Constructing Questionnaires Based on the Theory of Planned Behavior: A Manual for Health Services Researchers; Centre for Health Services Research: Newcastle Upon Tyne, UK, 2004.

106. Blanchard, C.M.; Fisher, J.; Sparling, P.B.; Shanks, T.H.; Rhodes, R.E.; Courneya, K.S.; Baker, F. Understanding adherence to 5 servings of fruits and vegetables per day: A theory of planned behavior perspective. J. Nutr. Educ. Behav. 2009, 41, 3-10. [CrossRef] [PubMed]

107. Ellis, R.; Kosma, M.; Cardinal, B.J.; Bauer, J.J.; McCubbin, J.A. Physical activity beliefs and behavior of adults with physical disabilities. Disabil. Rehabil. 2007, 29, 1221-1227. [CrossRef] [PubMed]

108. Blue, C. Does the theory of planned behavior identify diabetes-related cognitions for intention to be physically active and eat a healthy diet? Public Health Nurs. 2007, 24, 141-150. [CrossRef] [PubMed]

109. Tabak, N.; Ozon, M. The influence of nurses' attitudes, subjective norms and perceived behavioral control on maintaining patient's privacy in hospital setting. Nurs. Ethics 2004, 11, 366-377. [CrossRef] [PubMed]

110. Lam, T.; Hsu, C.H.C. Predicting Behavioral Intention of Choosing a Travel Destination. Tour. Manag. 2006, 27, 589-599. [CrossRef]

111. Sparks, E.; Pan, G.W. Chinese Outbound Tourists: Understanding their Attitudes, Constraints and Use of Information Sources. Tour. Manag. 2009, 30, 483-494. [CrossRef]

112. Cheng, S.; Lam, T.; Hsu, C.H.C. Negative Word-of-Mouth Communication Intention: An Application of the Theory of Planned Behaviour. J. Hosp. Tour. Res. 2006, 30, 95-116. [CrossRef]

113. Luna, D.; Gupta, S.F. An integrative framework for cross-cultural consumer behavior. Int. Mark. Rev. 2001, 18, 45-69. [CrossRef]

114. Solomon, M.R. Consumer Behavior: Buying, Having, and Being, Kindle ed.; Pearson Education Limited: Essex, UK, 2014.

115. Majeed, S.; Lu, C. Emotional Contagion through the Skincare Advertisements: The influence of culture on the Eastern Women Consumption Behavior. Eur. J. Bus. Manag. 2016, 8, 9-19.

116. Mooij, M.D.; Hofstede, G. Cross-Cultural Consumer Behavior: A Review of Research Findings. J. Int. Consum. Mark. 2011, 23, 181-192.

117. Majeed, S.; Lu, C.; Usman, M. Want to make me emotional? The influence of emotional advertisement on women consumption behavior. Front. Bus. Res. China 2017, 11, 16. [CrossRef]

118. Schumann, J.H.; Wangenheim, F.V.; Stringfellow, A.; Yang, Z.; Blazevic, V.; Praxmarer, S.; Shainesh, G.; Komor, M.; Shannon, R.M.; Jiménez, F.R. Cross-Cultural differences in the Effect of Received Word-of-Mouth Referral in Relational Service Exchange. J. Int. Mark. 2010, 8, 62-80. [CrossRef]

119. Roongrerngsuke, S.; Liefooghe, A. Attracting gold-collar workers: Comparing organizational attractiveness and work-related values across generations in China, India and Thailand. Asia Pac. Bus. Rev. 2013, 19, 337-355. [CrossRef]

120. Lee, G.; Lee, C. Cross-cultural comparison of the image of Guam perceived by Korean and Japanese travelers: Importance-performance analysis. Tour. Manag. 2009, 30, 922-931. [CrossRef]

121. Law, R. The Perceived Impact of Risks on Travel Decisions. Int. J. Tour. Res. 2006, 8, 289-300. [CrossRef]

122. Sönmez, S.F.; Graefe, A.R. Determining Future Travel Behavior from Past Travel Experience and Perceptions of Risk and Safety. J. Travel Res. 1998, 37, 172-177. [CrossRef]

123. Safavi, K. Patient-Centered Pay For Performance: Are We Missing The Target. J. Healthc. Manag. 2006, 51, 215-218. [CrossRef] [PubMed]

124. Van de Vijver, F.; Tanzer, N.K. Bias and equivalence in cross-cultural assessment: An overview. Eur. Rev. Appl. Psychol. 1997, 47, 263-280. [CrossRef]

125. Souro, J. What Is a Representative Sample Size for a Survey? 2010. Available online: http:/ / www.measuringu. com/survey-sample-size.php (accessed on 10 August 2017).

126. Bagozzi, R.P.; Yi, Y. On the evaluation of structural equation models. J. Acad. Mark. Sci. 1998, 16, 74-94. [CrossRef]

127. Hair, J.F.; Anderson, R.E.; Tatham, R.L.; Black, W. Multivariate Data Analysis, 5th ed.; Prentice-Hall International Inc.: Upper Saddle River, NJ, USA, 1998.

128. Fornell, C.; Larcker, D.F. Evaluating structural equation models with unob-serviable variables and measurement error. J. Mark. Res. 1981, 18, 39-50. [CrossRef]

129. Falk, R.F.; Miller, N.B. A Primer on Soft Modeling; Akron Press: Akron, OH, USA, 1992. 
130. Chin, W.W. The partial least squares approach for structural equation modeling. In Modern Methods for Business Research; Arcoulides, G.A., Ed.; Lawrence Erlbaum Associates: Mahwah, NJ, USA, 1988.

131. Hair, J.F.; Hult, G.T.; Ringle, C.; Sarstedt, M. A Primer on Partial Least Squares Structural Equation Modeling (PLS-SEM); Sage Publication: London, UK, 2013.

132. Zhao, X.; Lynch, J.G.; Chen, Q. Reconsidering baron and Kenny: Myths and truths about mediation analysis. J. Consum. Res. 2010, 37, 197-206. [CrossRef]

133. Ali, M.; Park, K. The mediating role of an innovative culture in the relationship between absorptive capacity and technical and non-technical innovation. J. Bus. Res. 2016, 69, 1669-1675. [CrossRef]

134. Yoo, B. Cross-group comparisons: A cautionary note. Psychol. Mark. 2012, 19, 357-368. [CrossRef]

(C) 2018 by the authors. Licensee MDPI, Basel, Switzerland. This article is an open access article distributed under the terms and conditions of the Creative Commons Attribution (CC BY) license (http://creativecommons.org/licenses/by/4.0/). 